\title{
TARP $\gamma-2$ and $\gamma-8$ Differentially Control AMPAR Density Across Schaffer Collateral/Commissural Synapses in the Hippocampal CA1 Area
}

\author{
Miwako Yamasaki, ${ }^{1}$ Masahiro Fukaya, ${ }^{1,2}$ Maya Yamazaki, ${ }^{3}$ Hirotsugu Azechi, ${ }^{3}$ Rie Natsume, ${ }^{3}$ Manabu Abe, ${ }^{3}$ \\ Kenji Sakimura, ${ }^{3}$ and $\odot$ Masahiko Watanabe ${ }^{1}$ \\ ${ }^{1}$ Department of Anatomy, Hokkaido University Graduate School of Medicine, Sapporo 060-8638, Japan, 2Department of Anatomy, Kitasato University \\ School of Medicine, Sagamihara, Kanagawa 252-0374, Japan, and ${ }^{3}$ Department of Cellular Neurobiology, Brain Research Institute, Niigata University, \\ Niigata 951-8585, Japan
}

The number of AMPA-type glutamate receptors (AMPARs) at synapses is the major determinant of synaptic strength and varies from synapse to synapse. To clarify the underlying molecular mechanisms, the density of AMPARs, PSD-95, and transmembrane AMPAR regulatory proteins (TARPs) were compared at Schaffer collateral/commissural (SCC) synapses in the adult mouse hippocampal CA1 by quantitative immunogold electron microscopy using serial sections. We examined four types of SCC synapses: perforated and nonperforated synapses on pyramidal cells and axodendritic synapses on parvalbumin-positive (PV synapse) and pravalbumin-negative interneurons (non-PV synapse). SCC synapses were categorized into those expressing high-density (perforated and PV synapses) or low-density (nonperforated and non-PV synapses) AMPARs. Although the density of PSD-95 labeling was fairly constant, the density and composition of TARP isoforms was highly variable depending on the synapse type. Of the three TARPs expressed in hippocampal neurons, the disparity in TARP $\gamma$-2 labeling was closely related to that of AMPAR labeling. Importantly, AMPAR density was significantly reduced at perforated and PV synapses in TARP $\gamma$-2-knock-out (KO) mice, resulting in a virtual loss of AMPAR disparity among SCC synapses. In comparison, TARP $\gamma-8$ was the only TARP expressed at nonperforated synapses, where AMPAR labeling further decreased to a background level in TARP $\gamma-8$-KO mice. These results show that synaptic inclusion of TARP $\gamma-2$ potently increases AMPAR expression and transforms low-density synapses into high-density ones, whereas TARP $\gamma-8$ is essential for low-density or basal expression of AMPARs at nonperforated synapses. Therefore, these TARPs are critically involved in AMPAR density control at SCC synapses.

Key words: AMPA receptor; hippocampus; interneuron; perforated synapse; pyramidal cell; transmembrane AMPAR regulatory proteins

Significance Statement

Although converging evidence implicates the importance of transmembrane AMPA-type glutamate receptor (AMPAR) regulatory proteins (TARPs) in AMPAR stabilization during basal transmission and synaptic plasticity, how they control large disparities in AMPAR numbers or densities across central synapses remains largely unknown. We compared the density of AMPARs with that of TARPs among four types of Schaffer collateral/commissural (SCC) hippocampal synapses in wild-type and TARP-knock-out mice. We show that the density of AMPARs correlates with that of TARP $\gamma-2$ across SCC synapses and its high expression is linked to high-density AMPAR expression at perforated type of pyramidal cell synapses and synapses on parvalbumin-positive interneurons. In comparison, TARP $\gamma-8$ is the only TARP expressed at nonperforated type of pyramidal cell synapses, playing an essential role in low-density or basal AMPAR expression.

\section{Introduction}

Most of the fast excitatory synaptic transmission in the brain is mediated by AMPA-type glutamate receptors (AMPARs), and

Received Nov. 20, 2015; revised Feb. 16, 2016; accepted Feb. 19, 2016.

Author contributions: M. Yamasaki and M.W. designed research; M. Yamasaki performed research; M. Yamazaki, H.A., R.N., M.A., K.S., and M.W. contributed unpublished reagents/analytic tools; M. Yamasaki and M.F. analyzed data; M. Yamasaki and M.W. wrote the paper. the number of synaptic AMPARs is the major determinant of synaptic strength. AMPARs are inserted into the extrasynaptic

This work was supported by the Ministry of Education, Culture, Sports, Science and Technology of Japan (Grantsin-Aid for Scientific Research 24220007 to M.W.); the Brain Mapping by Integrated Neurotechnologies for Disease Studies (Brain/MINDS Grant to M.W.); the Japan Agency for Medical Research and Development (AMED); and the Naito Foundation (Research Grant to M.Y.). We thank Yoichi M. Ito (Hokkaido University) for advice on statistical analyses. 
membrane by exocytosis, where they are highly mobile by lateral diffusion (Opazo et al., 2012). Subsequently, AMPARs are trapped at synapses through interaction with scaffolding proteins in the postsynaptic density (PSD) and removed by endocytosis or lateral diffusion (Malinow and Malenka, 2002; Bats et al., 2007; Opazo et al., 2012). The diffusional trapping and removal of AMPARs emphasizes the importance of the mechanisms that determine the synaptic strength. The number of AMPARs is differentially regulated at individual synapses in a target cell type-, input source-, and activity-dependent manner (Nusser et al., 1998; Matsuzaki et al., 2004; Yamasaki et al., 2011). The disparity in the number of synaptic AMPARs is considered to underlie efficient learning and information storage (Brunel et al., 2004; Barbour et al., 2007).

AMPARs are heterotetramers or homotetramers consisting of GluA1-GluA4 (GluR1-GluR4) subunits (Hollmann and Heinemann, 1994). The $C$-termini of GluA subunits bind different cytoplasmic proteins, yielding distinct trafficking, recycling, and synaptic plasticity mechanisms (Barry and Ziff, 2002; Malinow and Malenka, 2002; Song and Huganir, 2002). In addition to these principal subunits, most, if not all, neuronal AMPAR complexes contain transmembrane AMPAR regulatory proteins (TARPs) as essential auxiliary subunits (Yamazaki et al., 2004; Tomita et al., 2005). The TARP family comprises six isoforms: four classical or type-I $(\gamma-2, \gamma-3, \gamma-4$, and $\gamma-8)$ and two atypical or type-II ( $\gamma$-5 and $\gamma$-7) TARPs (Kato et al., 2008; Soto et al., 2009). TARPs interact with AMPARs and mediate their association with PSD-95, a key scaffolding protein in the PSD (Chen et al., 2000; Tomita et al., 2004). TARPs are involved in every aspect of AMPAR functions, from surface expression and synaptic targeting to gating and pharmacology (Ziff, 2007; Jackson and Nicoll, 2011b). Although converging evidence has shown the importance of TARPs in AMPAR stabilization during basal transmission and synaptic plasticity (Bats et al., 2007), it remains largely unknown how they contribute to disparities in AMPAR numbers or densities across synapses.

To address this issue, we focused on Schaffer collateral/commissural (SCC) synapses in the stratum radiatum of the hippocampal CA1 area. SCC synapses constitute the majority of synapses in the stratum radiatum (Sorra and Harris, 2000) and are formed on the dendritic spines of pyramidal cells and the dendritic shafts of GABAergic interneurons. Intriguingly, they exhibit highly skewed distributions of AMPARs depending on the synapse size, configuration, and distance from the soma (Nusser et al., 1998; Takumi et al., 1999; Racca et al., 2000; Matsuzaki et al., 2004; Nicholson et al., 2006; Shinohara et al., 2008). For example, SCC synapses on pyramidal cells are classified into perforated and nonperforated synapses based on the configuration of PSD. Perforated synapses contain more AMPARs than nonperforated synapses (Desmond and Weinberg, 1998; Nicholson et al., 2006) and have long been assumed to associate with structural expression of long-term potentiation (Lüscher et al., 2000).

By applying quantitative immunogold electron microscopy (EM) to serial ultrathin sections, we measured the density of AMPARs, PSD-95, and three classical TARPs expressed in hippocampal neurons at four types of SCC synapses. Here, we show

The authors declare no competing financial interests.

Correspondence should be addressed to Masahiko Watanabe, Department of Anatomy, Hokkaido University Graduate School of Medicine, Sapporo 060-8638, Japan. E-mail: watamasa@med.hokudai.ac.jp.

DOI:10.1523/JNEUROSCI.4178-15.2016

Copyright $\odot 2016$ the authors $\quad 0270-6474 / 16 / 364297-17 \$ 15.00 / 0$ that TARP $\gamma$-2 is enriched at perforated synapses on pyramidal cells and at synapses on parvalbumin (PV)-positive interneurons (PV synapses) and critically involved in their high-density expression of AMPARs. In contrast, TARP $\gamma-8$ is the only classical TARP expressed at nonperforated synapses on pyramidal cells, where it plays an essential role in the low-density or basal expression of AMPARs. These results suggest that the inclusion of specific TARP isoforms contribute influentially and differentially to the disparity of synaptic AMPAR expression, playing a role in AMPAR density control in a target cell type-, input source-, and activity-dependent manner.

\section{Materials and Methods}

Animals. We used male C57BL/6 wild-type (WT) mice and knock-out (KO) mice defective in GluA1, GluA2, GluA3, or GluA4 (Yamasaki et al., 2011) and in TARP $\gamma$-2 (Yamazaki et al., 2010), TARP $\gamma$-3, or TARP $\gamma$-8 (Fukaya et al., 2006) at the adult stage (2-4 months of age). TARP $\gamma-3-\mathrm{KO}$ mice were produced using the C57BL/6N ES cell line RENKA (Mishina and Sakimura, 2007), as reported previously (Fukaya et al., 2006; Yamazaki et al., 2010). All animal experiments were performed in accordance with the guidelines laid down by the animal welfare committees of Hokkaido University. The numbers of mice examined for respective experiments were as follows: in situ hybridization (WT, 6); immunofluorescence (WT, 9; TARP $\gamma$-2-KO, 3; TARP $\gamma$-3-KO, 3; TARP $\gamma$-8-KO, 3); quantitative postembedding immunogold and conventional electron microscopy (WT, 3; TARP $\gamma$-2-KO, 3; TARP $\gamma$-3-KO, 3 ; TARP $\gamma-8-\mathrm{KO}, 3)$.

In situ hybridization. We used isotopic in situ hybridization using ${ }^{33} \mathrm{P}-$ dATP-labeled 45-mer antisense oligonucleotide probes for GluA1GluA4 mRNAs (Hashimoto et al., 1999) and non-isotopic in situ hybridization with fluorescein-, digoxigenin (DIG)-, or biotin-labeled cRNA probes for GluA1 (nt 344-1183 bp, GenBank accession \#NM_ 001113325), GluA2 (nt 408-1247 bp, GenBank accession \#NM_001083806), GluA3 (nt 262-1101 bp, GenBank accession \#NM_016886), GluA4 (nt 262$1250 \mathrm{bp}$, GenBank accession \#AB102777), $67 \mathrm{kDa}$ glutamic acid decarboxylase (GAD67; nt 1036-2015 bp, GenBank accession \#NM_008077), neuropeptide Y (NPY; nt 1-495 bp, GenBank accession \#NM_023456), parvalbumin (PV; nt 57-389 bp, GenBank accession \#NM_013645), cholecystokinin (CCK; nt 1-658 bp, GenBank accession \#NM_ 031161), neuronal nitric oxide synthase (nNOS; nt 99-1175 bp, GenBank accession \#NM_008712), TARP $\gamma-2$ (nt 584-1360 bp, GenBank accession \#AF077739), TARP $\gamma$-3 (nt 195-950 bp, GenBank accession \#AJ272044), and TARP $\gamma$-8 (nt 817-1380 bp, GenBank accession \#NM_133190) mRNAs. cRNA probes were synthesized by in vitro transcription using the Bluescript II plasmid vector encoding the above cDNAs as described previously (Yamasaki et al., 2010). The specificity of GluA1-GluA4 and GAD67 was reported in Yamasaki et al. (2011).

Under deep pentobarbital anesthesia (100 mg/kg body weight, i.p.), brains were freshly obtained and immediately frozen in powdered dry ice. Fresh frozen sections $(20 \mu \mathrm{m})$ were cut on a cryostat (CM1900; Leica Microsystems) and mounted on silane-coated glass slides. Sections were treated successively: fixation with $4 \%$ paraformaldehyde- $0.1 \mathrm{~m}$ sodium phosphate buffer (PB), pH 7.2, for $10 \mathrm{~min}$, PBS, pH 7.2, for $10 \mathrm{~min}$, acetylation with $0.25 \%$ acetic anhydride in $0.1 \mathrm{M}$ triethanolamine- $\mathrm{HCl}$, $\mathrm{pH} 8.0$, for $10 \mathrm{~min}$, and prehybridization for $1 \mathrm{~h}$ in a buffer containing $50 \%$ formamide, $50 \mathrm{~mm}$ Tris- $\mathrm{HCl}, \mathrm{pH}$ 7.5, $0.02 \%$ Ficoll, $0.02 \%$ polyvinylpyrrolidone, $0.02 \%$ bovine serum albumin, $0.6 \mathrm{M} \mathrm{NaCl}, 200 \mu \mathrm{g} / \mathrm{ml}$ tRNA, 1 mm EDTA, and 10\% dextran sulfate. Isotopic in situ hybridization was performed at $42^{\circ} \mathrm{C}$ for $12 \mathrm{~h}$ in prehybridization buffer supplemented with oligonucleotide $(10,000 \mathrm{dpm} / \mu \mathrm{l})$, followed by washing in $0.1 \times$ SSC containing $0.1 \%$ SDS at $55^{\circ} \mathrm{C}$ for 40 min twice and exposure to $\mathrm{X}$-ray film BioMax (Kodak,).

FISH was performed at $63.5^{\circ} \mathrm{C}$ for $12 \mathrm{~h}$ in hybridization buffer supplemented with a mixture of cRNA probes at a dilution of 1:1000. Posthybridization washing was done at $61^{\circ} \mathrm{C}$ successively with $5 \times$ SSC for 30 min, $4 \times$ SSC containing $50 \%$ formamide for $40 \mathrm{~min}, 2 \times$ SSC containing $50 \%$ formamide for $40 \mathrm{~min}$, and $0.1 \times$ SSC for $30 \mathrm{~min}$. Sections were 
Table 1. Details of primary antibodies used

\begin{tabular}{|c|c|c|c|c|}
\hline Molecule & Sequence (NCBI \#) & Host & Specificity & Reference \\
\hline GluA1 & 841-907 ad (X57497) & $\mathrm{Rb}, \mathrm{GP}$ & $\mathrm{IB} / \mathrm{KO}(\mathrm{IF}, \mathrm{IE})$ & Yamazaki et al., 2010, Yamasaki et al., 2011 \\
\hline GluA2 & 847-863 aа (X57498) & $\mathrm{Rb}, \mathrm{GP}$ & $\mathrm{IB} / \mathrm{KO}$ (IF, IE) & Yamazaki et al., 2010, Yamasaki et al., 2011 \\
\hline GluA3 & 853-883 aа (AB022342) & $\mathrm{Rb}, \mathrm{GP}, \mathrm{Go}$ & IB/KO (IF, IE) & Yamazaki et al., 2010, Yamasaki et al., 2011 \\
\hline pan-AMPAR & $727-745$ aа (X57497) & GP & IB/HEK & Fukaya et al., 2006 \\
\hline PSD-95 & 1-62 aа (D50621) & $\mathrm{Rb}, \mathrm{GP}$ & $\mathrm{IB}$ & Fukaya and Watanabe, 2000 \\
\hline PV & 1-110 aa (NM_013645) & $\mathrm{Pb}, \mathrm{GP}, \mathrm{G}_{0}$ & IB & Nakamura et al., 2004, Miura et al., 2006 \\
\hline TARP $\gamma-8$ & 362-421 aа (AF361350) & $\mathrm{Rb} / \mathrm{GP}$ & IB/HEK/KO (IF, IE) & Fukaya et al., 2006 \\
\hline
\end{tabular}

Go, Goat polyclonal antibody; GP, guinea pig polyclonal antibody; HEK, immunoblot with transfected HEK cell lysates; IB, immunoblot with brain homogenates; KO (IF, IE), lack of immunolabeling was confirmed by immunofluorescence (IF) and postembedding immunogold (IE) using knockout brains; pan-AMPAR, pan-AMPAR antibody was raised against the sequence common to all four GluA subunits; Rb, rabbit polyclonal antibody.

incubated at room temperature in NTE buffer $(0.5 \mathrm{M} \mathrm{NaCl}, 0.01 \mathrm{M}$ Tris$\mathrm{HCl}, \mathrm{pH} 7.5$, and $5 \mathrm{~mm}$ EDTA) for $20 \mathrm{~min}, 20 \mathrm{~mm}$ iodoacetamide in NTE buffer for $20 \mathrm{~min}$, and TNT buffer $(0.1 \mathrm{M}$ Tris- $\mathrm{HCl}, \mathrm{pH} 7.5$, and $0.15 \mathrm{M}$ $\mathrm{NaCl}$ ) for $20 \mathrm{~min}$. For double- or triple-labeling FISH, each reporter molecule was visualized separately. First, fluorescein was visualized with peroxidase-conjugated anti-fluorescein antibody (Invitrogen; 1:1500, $1 \mathrm{~h}$ ) and the FITC-TSA plus amplification kit (PerkinElmer). Second, DIG was visualized with peroxidase-conjugated anti-DIG antibody (Roche Diagnostics, 1:500, $1 \mathrm{~h}$ ) and the Cy3-TSA plus amplification kit (PerkinElmer). Third, biotin was visualized with peroxidase-conjugated anti-biotin antibody (Vector Laboratories, $2 \mu \mathrm{g} / \mathrm{ml}, 1 \mathrm{~h}$ ) and the Cy5TSA plus amplification kit (PerkinElmer). Residual activities of peroxidase introduced in the prior detection were inactivated by incubation of sections with $1 \% \mathrm{H}_{2} \mathrm{O}_{2}$ for $30 \mathrm{~min}$. Sections selected for doublelabeling FISH were further stained with NeuroTrace 640/660 Nissl stain (Invitrogen).

Photographs were taken with a confocal laser-scanning microscope (FV1000; Olympus) equipped with a HeNe/Ar laser, and PlanApo $(10 \times /$ $0.40)$ and PlanApoN (60×/1.42, oil-immersion) objective lenses (Olympus). Fluorescence cross talk was prevented by restricting the width of the emission wavelength using spectral slit and by adopting the sequential mode of laser scanning. All images represent single optical sections $(640 \times 640$ pixels, pixel size $110 \mathrm{~nm})$.

Expression levels of mRNA were evaluated semiquantitatively from confocal images taken with appropriate gain-level settings. Separate color components were converted to grayscale and the gray level (arbitrary units) and area were measured using MetaMorph software (Molecular Devices) from individual somata of GAD67 or other marker mRNA-positive interneurons or from Nissl-stained small neurons in the pyramidal cell layer (i.e., pyramidal cells). For normalizing expression levels, the gray level of individual cells in each interneuron type was divided by the mean gray level of 100 pyramidal cells in the same field of view. In the present study, statistical comparisons of the expression level were made between pyramidal cells and GAD67-positive cells and among PV-, CCK-, and nNOS/NPY-expressing interneurons.

Antibodies. We used primary antibodies against GluA1-GluA4, PSD95, PV, TARP $\gamma$-2, TARP $\gamma$-3, and TARP $\gamma$-8. Of these, we produced in the present study an affinity-purified TARP $\gamma$-3 antibody, which was raised against aa residues $290-310$ of mouse TARP $\gamma$-3 (NM_019430). Information on the sequence of antigens, host species, specificity, and references of each primary antibody is summarized in Tables $1,2,3$, and 4 .

The specificity of the TARP $\gamma-3$ antibody was confirmed by immunoblot detection of a protein band at $32-35 \mathrm{kDa}$ in brain homogenates and HEK293T lysates transfected with TARP $\gamma$-3, but not TARP $\gamma$-2, TARP $\gamma-4$, or TARP $\gamma-8$ (data not shown), and by blank immunohistochemical labeling in TARP $\gamma$-3-KO brains at light and electron microscopic levels (see Fig. 7B, Table 3). The specificity of other TARP antibodies and GluA1-GluA4 antibodies was confirmed by intense labeling in WT brains and almost blank labeling in the corresponding GluA-KO and TARP-KO brains (Tables 2, 3), whereas that of pan-AMPAR and PSD-95 antibodies was confirmed by exclusive labeling of asymmetrical synapses in WT mice (Table 4, top). The specificity of PV antibody was supported by intense immunogold labeling in the cytoplasm of dendritic shafts
Table 2. Immunogold labeling using AMPAR and TARP antibodies in WT mice

\begin{tabular}{|c|c|c|c|c|c|c|c|c|c|}
\hline \multirow[b]{3}{*}{$A b$} & \multicolumn{9}{|c|}{ Density } \\
\hline & \multicolumn{3}{|c|}{ PSD membrane } & \multicolumn{3}{|c|}{ Non-PSD membrane } & \multicolumn{3}{|c|}{ Cytoplasm } \\
\hline & Mean & SEM & $\mathrm{L}$ & Mean & SEM & $\mathrm{L}$ & Mean & SEM & $S$ \\
\hline \multicolumn{10}{|l|}{ GluA1 } \\
\hline$S P$ & 7.7 & 0.6 & 41.2 & 0.4 & 0.1 & 51.3 & 1.5 & 0.8 & 4.5 \\
\hline PV & 17.9 & 1.5 & 30 & 0.3 & 0.2 & 20.4 & 6.6 & 1.8 & 26.7 \\
\hline$n P V$ & 11.8 & 2.3 & 4.3 & 0.4 & 0.4 & 17.1 & 6.7 & 2.1 & 5.3 \\
\hline$S P$ & 6.8 & 0.8 & 44.4 & 0.6 & 0.2 & 47.7 & 8.8 & 2.1 & 3.8 \\
\hline \multicolumn{10}{|l|}{ GluA2 } \\
\hline PV & 4.5 & 0.7 & 19.3 & 0.6 & 0.2 & 15.2 & 3.6 & 1.2 & 7.6 \\
\hline $\mathrm{nPV}$ & 3.1 & 1 & 4.2 & 0.8 & 0.5 & 13.7 & 3.9 & 1.2 & 5 \\
\hline SP & 1.9 & 0.4 & 29.4 & 0 & 0 & 48.4 & 1.5 & 0.8 & 4.3 \\
\hline \multicolumn{10}{|l|}{ GluA3 } \\
\hline PV & 10 & 0.8 & 30.3 & 0.1 & 0.1 & 17.1 & 2.6 & 0.8 & 8 \\
\hline $\mathrm{nPV}$ & 3 & 1.1 & 5.1 & 0 & 0 & 10.9 & 1.3 & 0.5 & 10.1 \\
\hline SP & 0.2 & 0.1 & 23.1 & 0 & 0 & 50.9 & 1.8 & 0.8 & 4.5 \\
\hline \multicolumn{10}{|l|}{ GluA4 } \\
\hline PV & 12 & 0.9 & 27.3 & 0.2 & 0.1 & 21.6 & 4.9 & 1.1 & 8.1 \\
\hline$n P V$ & 1.7 & 0.8 & 4.3 & 0.3 & 0.2 & 10.5 & 3.5 & 0.8 & 8 \\
\hline \multicolumn{10}{|l|}{ TARP $\gamma 2$} \\
\hline$S P$ & 1.5 & 0.3 & 34 & 0 & 0 & 54.8 & 1 & 0.5 & 5.3 \\
\hline PV & 23.3 & 1.1 & 19 & 0.1 & 0.1 & 18.5 & 1.5 & 0.6 & 9.4 \\
\hline$n P V$ & 9.7 & 0.8 & 6.6 & 0 & 0 & 11.2 & 0.2 & 0.1 & 6.5 \\
\hline \multicolumn{10}{|l|}{ TARP $\gamma 3$} \\
\hline$S P$ & 0.5 & 0.2 & 18.8 & 0 & 0 & 43.5 & 0 & 0 & 3.6 \\
\hline PV & 5.2 & 0.7 & 23.9 & 0.1 & 0.1 & 12.9 & 1.5 & 0.4 & 13.6 \\
\hline$n P V$ & 1.5 & 1.1 & 2.5 & 0 & 0 & 4.5 & 1.6 & 0.9 & 3.1 \\
\hline \multicolumn{10}{|l|}{ TARP $\gamma 8$} \\
\hline$S P$ & 14.9 & 1 & 45.7 & 1.1 & 0.2 & 51 & 20.3 & 3.2 & 4.4 \\
\hline PV & 18 & 1.3 & 20.2 & 0.5 & 0.1 & 9.6 & 2.7 & 0.9 & 10.4 \\
\hline $\mathrm{nPV}$ & 15.1 & 2.2 & 8 & 1.7 & 0.7 & 6.9 & 5.4 & 1.5 & 6.3 \\
\hline
\end{tabular}

The density of immunogold labeling in the synaptic (PSD) membrane, nonsynaptic (non-PSD) membrane, and cytoplasm of control mice was calculated as linear density $(/ \mu \mathrm{m})$ or areal density $\left(/ \mu \mathrm{m}^{2}\right)$ by quantitative doublelabeling postembedding immunogold EM. Single ultrathin sections were incubated with a mixture of PV antibody and any of GluA1-GluA4 and TARP $\gamma-2, \gamma-3$, and $\gamma-8$ antibodies. Data were collected from two WT mice. Values significantly higher than those in the corresponding $\mathrm{KO}$ mice (Table 3 ) are indicated in bold italic ( $p<0.01, U$ test) or bold ( $p<0.05, U$ test). Ab, Primary antibody; SP, dendritic spine on pyramidal cells; PV, PV-positive dendrites; nPV, PV-negative dendrites; L, measured length; $S$, measured area.

forming high-density asymmetrical synapses, a morphological hallmark of PV-positive interneurons (Baude et al., 1995; Gulyás et al., 1999). In the present analysis, PV-positive dendrites were defined as those labeled with immunogold at densities $>10$ particles $/ \mu \mathrm{m}^{2}$ in consecutive sections. The mean labeling density in PV-positive dendrites $17.4 \pm 1.5 /$ $\mu \mathrm{m}^{2}$ and below $0.2 \pm 0.1 / \mu \mathrm{m}^{2}$ in PV-negative dendrites (see Fig. 1 , Table 4 , bottom), with no overlapping populations at $10 / \mu \mathrm{m}^{2}$.

Immunofluorescence. For immunofluorescence, mice under deep pentobarbital anesthesia were fixed transcardially with $4 \%$ paraformaldehyde in $0.1 \mathrm{M} \mathrm{PB}, \mathrm{pH}$ 7.2. Brains were cut in the midline and a pair of right halves of WT and KO brains were embedded in single paraffin blocks to be subjected to immunohistochemical incubations under the same con- 
Table 3. Immunogold labeling using AMPAR and TARP antibodies in KO mice

\begin{tabular}{|c|c|c|c|c|c|c|c|c|c|}
\hline \multirow[b]{3}{*}{$A b$} & \multicolumn{9}{|c|}{ Density } \\
\hline & \multicolumn{3}{|c|}{ PSD membrane } & \multicolumn{3}{|c|}{ Non-PSD membrane } & \multicolumn{3}{|c|}{ Cytoplasm } \\
\hline & Mean & SEM & $\mathrm{L}$ & Mean & SEM & L & Mean & SEM & $S$ \\
\hline \multicolumn{10}{|l|}{ GluA1 } \\
\hline SP & 0.7 & 0.5 & 14.5 & 0.1 & 0.1 & 45.2 & 1.5 & 1 & 3.2 \\
\hline PV & 0.3 & 0.2 & 7.4 & 0.1 & 0.1 & 28.3 & 1.5 & 0.3 & 15.7 \\
\hline$n P V$ & 0.1 & 0.1 & 2.8 & 0.1 & 0.1 & 10.5 & 1.5 & 0.9 & 5.2 \\
\hline SP & 0.1 & 0.1 & 12.7 & 0.1 & 0.1 & 39.5 & 0.5 & 0.5 & 2.9 \\
\hline \multicolumn{10}{|l|}{ GluA2 } \\
\hline PV & 0.1 & 0.1 & 19.2 & 0 & 0 & 28.5 & 0.9 & 0.3 & 17.9 \\
\hline$n P V$ & 0.1 & 0 & 3.1 & 0.1 & 0.1 & 9.8 & 0.1 & 0.1 & 4.5 \\
\hline SP & 0.1 & 0.1 & 11.7 & 0 & 0 & 42.2 & 0 & 0 & 3.3 \\
\hline \multicolumn{10}{|l|}{ GluA3 } \\
\hline PV & 0.1 & 0.1 & 11.1 & 0 & 0 & 21.3 & 0.4 & 0.2 & 20.8 \\
\hline$n P V$ & 0.1 & 0.1 & 2.8 & 0 & 0 & 7.9 & 0.1 & 0.1 & 4.3 \\
\hline SP & 0.5 & 0.5 & 12.6 & 0 & 0 & 41.4 & 4.7 & 1.9 & 3 \\
\hline \multicolumn{10}{|l|}{ GluA4 } \\
\hline PV & 0.1 & 0.1 & 14.1 & 0 & 0 & 29.5 & 2.4 & 0.7 & 20 \\
\hline nPV & 0 & 0.1 & 3.2 & 0 & 0 & 10.1 & 2.5 & 0.9 & 3.9 \\
\hline \multicolumn{10}{|l|}{ TARP $\gamma 2$} \\
\hline SP & 0.4 & 0.4 & 7.8 & 0 & 0 & 41.8 & 3.5 & 1.6 & 3.4 \\
\hline PV & 2 & 0.5 & 15.6 & 0.4 & 0.2 & 17 & 3.9 & 1 & 9.5 \\
\hline nPV & 1 & 0.5 & 2.8 & 0 & 0 & 8.8 & 2.2 & 1.1 & 4.2 \\
\hline \multicolumn{10}{|c|}{ TARP $\gamma 3$} \\
\hline SP & 0 & 0 & 9.5 & 0 & 0 & 44.4 & 0.5 & 0.3 & 3.8 \\
\hline PV & 0.5 & 0.3 & 6.2 & 0 & 0 & 17.8 & 0.9 & 0.4 & 8.6 \\
\hline$n P V$ & 0.5 & 0.5 & 2 & 0 & 0 & 4.8 & 2.2 & 0.1 & 3.6 \\
\hline \multicolumn{10}{|c|}{ TARP $\gamma 8$} \\
\hline SP & 0.3 & 0.2 & 6.3 & 0.1 & 0.1 & 38.1 & 1 & 0.4 & 3.3 \\
\hline PV & 0 & 0 & 3.8 & 0 & 0 & 15 & 0 & 0 & 7.7 \\
\hline$n P V$ & 1 & 1 & 2.8 & 0 & 0 & 5 & 1.6 & 0.8 & 2.8 \\
\hline
\end{tabular}

The density of immunogold labeling was measured when a mixture of PV antibody and any of GluA1-GluA4 and TARP $\gamma-2, \gamma-3$, and $\gamma-8$ antibodies was applied to the corresponding GluA-K0 or TARP-K0 mice. Data were collected from two KO mice. See Table 2 for explanation and abbreviations.

Table 4. Specificity of pan-AMPAR, PSD-95, and PV antibodies

\begin{tabular}{|c|c|c|c|}
\hline \multirow[b]{3}{*}{$\mathrm{Ab}$} & \multicolumn{3}{|c|}{ Density } \\
\hline & \multicolumn{3}{|c|}{ PSD membrane } \\
\hline & Mean & SEM & L \\
\hline \multicolumn{4}{|l|}{ pAMPAR } \\
\hline Asym & 12.4 & 3.5 & 5.9 \\
\hline Sym & 0 & 0 & 3.9 \\
\hline \multicolumn{4}{|l|}{ PSD-95 } \\
\hline Asym & 41.8 & 3 & 7.2 \\
\hline \multirow[t]{3}{*}{ Sym } & 0 & 0 & 6.3 \\
\hline & \multicolumn{3}{|c|}{ Cytoplasm } \\
\hline & Mean & SEM & $S$ \\
\hline \multicolumn{4}{|l|}{ PV } \\
\hline SP & 0.4 & 0.2 & 15 \\
\hline PV & 17.3 & 1.5 & 34.6 \\
\hline$n P V$ & 0.2 & 0.1 & 32.3 \\
\hline
\end{tabular}

The density of immunogold labeling for AMPARs (pAMPAR) and PSD-95 in the synaptic (PSD) membrane (/ $\mu \mathrm{m}$ ) or for PV in the cytoplasm $\left(/ \mu \mathrm{m}^{2}\right)$ was measured from two WT mice. The PSD membrane at asymmetrical synapses has significantly higher densities of immunogold labeling for AMPARs and PSD-95 than that at symmetrical synapses $(p<0.01$ each, $U$ test). PV-positive dendrites have significantly higher density of immunogold labeling for PV than dendritic spines of pyramidal cells and PV-negative dendrites ( $p<0.01, U$ test). See Table 2 for explanation and abbreviations.

ditions. Paraffin sections ( $4 \mu \mathrm{m}$ in thickness) were made by a sliding microtome (SM2000R; Leica Microsystems) and mounted on silanecoated glass slides. All immunohistochemical incubations were performed at room temperature and $10 \%$ normal donkey serum was used for blocking. To expose antigens of GluA subunits and TARPs, paraffin sections were pretreated with $1 \mathrm{mg} / \mathrm{ml}$ pepsin $(\mathrm{DAKO})$ in $0.2 \mathrm{~N} \mathrm{HCl}$ at $37^{\circ} \mathrm{C}$ for $10 \mathrm{~min}$, as reported previously (Watanabe et al., 1998). For single immunofluorescence, sections were incubated with primary antibodies $(1 \mu \mathrm{g} / \mathrm{ml})$ overnight, followed by successive incubation with biotinylated secondary antibodies for $2 \mathrm{~h}$, avidin-biotin-peroxidase complex for $1 \mathrm{~h}$, and tyramide signal amplification (TSA) amplification for $10 \mathrm{~min}$ using the TSA-Cy3 and TSA-Fluorescein system (PerkinElmer). For triple immunofluorescence, sections were incubated with a mixture of primary antibodies $(1 \mu \mathrm{g} / \mathrm{ml})$ overnight and then with Alexa Fluor 488-, Cy3-, or Cy5-conjugated secondary antibodies for $2 \mathrm{~h}$.

Photographs of whole-brain images were taken using a fluorescent microscope (AX-70; Olympus) and hippocampal and magnified images were obtained using a confocal laser-scanning microscope (FV1000, Olympus) as described in the "In situ hybridization" section.

Postembedding immunogold electron microscopy. Mice under deep pentobarbital anesthesia were fixed transcardially with $4 \%$ paraformaldehyde in $0.1 \mathrm{M} \mathrm{PB}, \mathrm{pH} 7.2$, and sagittal microslicer sections $(400 \mu \mathrm{m})$ were made from the right dorsal hippocampus located in 400-1200 $\mu \mathrm{m}$ lateral from the midline. After $4 \mathrm{~h}$ of postfixation in the same fixative, sections were cryoprotected with $30 \%$ glycerol in $\mathrm{PB}$ and frozen rapidly with liquid propane in the EM CPC unit (Leica Microsystems). Frozen sections were immersed in $0.5 \%$ uranyl acetate in methanol at $-90^{\circ} \mathrm{C}$ in the AFS freeze-substitution unit (Leica Microsystems), infiltrated at $-45^{\circ} \mathrm{C}$ with Lowicryl HM-20 resin (Electron Microscopy Sciences), and polymerized with UV.

Ultrathin sections were made from the CA1 region located in the midway between the subiculum and CA2 using an Ultracut ultramicrotome (Leica Microsystems). Electron micrographs were taken from the proximal half of the stratum radiatum of the dorsal hippocampal CA1 region (20-80 $\mu \mathrm{m}$ distal from the stratum pyramidale). For quantitative immunogold analyses, the same series of sections were incubated simultaneously. Sections were etched with saturated sodium-ethanolate solution for $1-5 \mathrm{~s}$. They were treated successively with the following solutions: the blocking solution [ $2 \%$ normal goat serum in the incubation solution (0.03\% Triton X-100 in TBS, pH 7.4; TTBS)] for $20 \mathrm{~min}$, primary antibody $(20 \mu \mathrm{g} / \mathrm{ml}$ for each antibody diluted with the blocking solution) overnight, and colloidal gold (10 $\mathrm{nm}$ in diameter)-conjugated anti-rabbit or anti-guinea pig $\operatorname{IgG}(1: 100$, British BioCell International) in the blocking solution for $2 \mathrm{~h}$. After extensive washing in TTBS, grids were incubated with $2 \%$ normal rabbit serum for $30 \mathrm{~min}$ and then overnight with rabbit anti-PV antibody-conjugated colloidal immunogold $(15 \mathrm{~nm})$ prepared according to the method of Slot and Geuze (1985). Finally, the grids were washed in TTBS and distilled water for $30 \mathrm{~min}$ and then stained with $1 \% \mathrm{OsO}_{4}$ for $20 \mathrm{~min}, 5 \%$ uranyl acetate $/ 40 \% \mathrm{EtOH}$ for $90 \mathrm{~s}$, and Reynold's lead citrate solution for $1 \mathrm{~min}$.

Sampling and quantification of postembedding immunogold labeling. For single section analyses (Tables 2, 3, 4), ultrathin sections were mounted on 400 mesh nickel grids precoated with neoprene W (Nisshin). Photographs were taken with an H-7100 electron microscope (Hitachi) at 10,000 $\times$ magnification and negative films corresponding to an area of $\sim 45 \mu \mathrm{m}^{2}$ were scanned at $1200 \mathrm{dpi}$. For quantitative analysis, postsynaptic and nonsynaptic membrane-associated immunogold particles, defined as those $<35 \mathrm{~nm}$ apart from the cell membrane, and cytoplasmic immunogold particles were counted and the length of the PSD and nonsynaptic membrane and the area of each compartment were measured using MetaMorph software (Molecular Devices). Labeling density was obtained by dividing the total number of immunogold particles by the total length or area of each profile.

For serial section analyses (Figs. 1, 3, 5, 8, 9, 10), each Lowicryl block was trimmed into a trapezoid ( $\sim 300 \mu \mathrm{m}$ wide and $\sim 180 \mu \mathrm{m}$ height $)$ that contained the stratum pyramidale and the stratum radiatum of the CA1 region. On average, the area of the trapezoid was 5.2, 4.8, 4.4, and $4.0(\times$ $10^{4} \mu \mathrm{m}^{2}$ ) from WT, TARP- $\gamma 2-\mathrm{KO}$, TARP- $\gamma 3-\mathrm{KO}$, and TARP- $\gamma 8-\mathrm{KO}$ mice, respectively. A ribbon of consecutive 15-25 sections was mounted on each single-slot nickel grid supported by Formvar membrane. Average thickness of sections was estimated to be consistently $\sim 90 \mathrm{~nm}$ based on the homogeneity of interference color of the sections floating on the water in a boat of diamond knife (Meek, 1976), as well as the estimated value obtained from the minimal folds method with modification (Small, 1968; Kubota et al., 2009). Immunoreacted sections were viewed at $80 \mathrm{KV}$ 
on a JEM-1400 transmission electron microscope (JOEL). Two different fields of view containing at least one PV-positive or PV-negative dendrite were chosen from each mouse, and images having an area of $\sim 32 \mu \mathrm{m}^{2}$ were captured from 10-20 consecutive sections using a $1 \mathrm{k}$ CCD camera (C4742-95-12ER; Hamamatsu Photonics) at 20,000 $\times$ magnification (1000 pixel/inch). In general, $3-4,7-8$, or 3-4 consecutive sections sufficed to "cover" the entire nonperforated synapses, perforated synapses, or axodendritic interneuron synapses, respectively. On average, 68.1, $71.1,61.0$, and 68.8 sections from WT, TARP- $\gamma-2-\mathrm{KO}$, TARP- $\gamma-3-\mathrm{KO}$, and TARP- $\gamma-8-\mathrm{KO}$, respectively, were used in the analyses using each antibody. Synapses were sampled for quantitative analysis only if they were clearly identified and fully included within serially sectioned volumes of the tissue. The length of PSD was measured on each ultrathin section and summed from all sections through each synapse. Linear labeling density was calculated by dividing the total number of immunogold particles by the total length of PSD at individual synapses. There were no significant differences in the total PSD length of synapses from the same categories among analyses using different antibodies or mouse lines. Results of Kruskal-Wallis (KW) test were as follows: $p=0.30,0.14$, 0.18 , and 0.20 at perforated, nonperforated, PV, and non-PV synapses, respectively.

Conventional serial electron microscopy. To calculate the percentage of perforated and nonperforated synapses on pyramidal cell spines, 20-30 serial ultrathin sections were made from the same Lowicryl blocks used in the postembedding immunogold. They were mounted on Formvarcoated copper single-slot grids and stained with $1 \% \mathrm{OsO}_{4}$ for $20 \mathrm{~min}, 5 \%$ uranyl acetate $/ 40 \%$ EtOH for $90 \mathrm{~s}$, and Reynold's lead citrate solution for $1 \mathrm{~min}$. Two different fields of view per mouse were chosen from the similar zone in the postembedding immunogold EM analyses. Sections were imaged at $80 \mathrm{KV}$ on a JEM-1400 transmission electron microscope (JOEL) and images having an area of $\sim 49 \mu \mathrm{m}^{2}$ were captured from 20 consecutive sections using a $1 \mathrm{k}$ CCD camera (C4742-95-12ER; Hamamatsu Photonics) at $15,000 \times$ magnification (1000 pixel/inch). Synapses were sampled only if they were clearly identified and fully included within serially sectioned volumes of the tissue. The number of synapses reconstructed from each mouse line was 2748, 2778, and 2804 from WT, TARP- $\gamma 2-\mathrm{KO}$, and TARP- $\gamma 8-\mathrm{KO}$ mice, respectively.

Statistical analyses. All values are expressed as the mean \pm SEM (where $n=$ number of analyzed synapses or neurons unless otherwise noted). Statistical tests were performed using SPSS 22.0 software (IBM). Before analysis, we tested the normality of all quantitative data using Kolmogorov-Smirnov and Shapiro-Wilk tests, as well as the homogeneity of variance by Levene's test. Because some of the datasets in this study violated the assumptions of normality and/or homogeneity of variance, comparisons of two groups were performed using a two-tailed Welch's unequal variances $t$ test, which is a parametric test robust in the face of violations in normality, and two-tailed Mann-Whitney $U$ test ( $U$ test), the nonparametric equivalent of the $t$ test. We confirmed that parametric and nonparametric statistics resulted in $p$-values of the same order of magnitude; therefore, only the $p$-values from the $U$ test are presented in Results, but data are presented as mean \pm SEM. For three or more group comparisons, KW test with post hoc Scheffe's multiple-comparisons procedure was performed. For assessment of the relationship between AMPAR labeling density and total PSD length, the Pearson correlation coefficient was calculated. For further assessment of the relationship among synapse type, PSD size, and AMPAR, labeling density was performed with a twoway ANOVA, which is generally robust to moderate deviations from normality (Glass et al., 1972). In semiquantitative FISH analyses, experiments from different sections and animals were pooled because no significant difference was observed in normalized fluorescent intensity. In quantitative postembedding immunogold analyses, measurements in two to three animals of the same mouse line were pooled because no significant difference was observed for labeling density or total PSD length using the KW test. Differences were considered statistically significant at $p<0.05$.

\section{Results}

To clarify the synapse-type-dependent regulation and mechanisms of AMPAR expression, we applied postembedding immu- nogold EM to serial ultrathin sections covering the entire PSD of given SCC synapses and measured the density of immunogold labeling from the total number of immunogold particles and the total PSD length at given synapses on serial sections.

\section{Heterogeneous density of AMPARs}

When viewed in serial EM sections, SCC synapses on dendritic spines of pyramidal cells (Fig. 1A) could be classified, by the different configurations of PSDs, into two subtypes: perforated synapses with fenestrated, horseshoe-shaped, or segmented PSD (Fig. $1 B, C$ ) and nonperforated synapses with continuous disklike PSD in all sections (Fig. 1D). Consistent with previous reports in rats (Ganeshina et al., 2004; Nicholson et al., 2006), the majority of SCC synapses on dendritic spines were nonperforated synapses $(92.7 \pm 0.83 \%, n=6$ fields of view, from 3 mice), with the rest being perforated synapses $(7.3 \pm 0.83 \%)$.

The two types of SCC synapses exhibited striking differences in immunogold labeling for AMPARs. Using a pan-AMPAR antibody raised against the sequence common to all four GluA subunits (Fukaya et al., 2006), immunogold particles were observed in all perforated synapses ( 48 of 48 synapses; Fig. $1 A-C$ ), but only in $40 \%$ of nonperforated synapses (60 of 150 synapses; Fig. $1 A, D)$. The mean density of AMPAR labeling was five times higher at perforated synapses than at nonperforated synapses (Fig. $1 E$, left; $p<0.01, U$ test). The total PSD length measured from perforated synapses was twice larger than that from nonperforated synapses $(0.52 \pm 0.02 \mu \mathrm{m}$ and $0.25 \pm 0.01 \mu \mathrm{m}$ from perforated and nonperforated synapses, respectively, $p<0.01, U$ test). When the density of AMPAR labeling at individual synapses was plotted as a function of the total PSD length (Fig. 1E, right), no significant correlation was found between the two parameters at both perforated and nonperforated synapses [Pearson correlation coefficient $(r)=0.12$ and 0.17 , respectively; $p=0.16$ and 0.25 , respectively]. To further examine whether labeling density was independent of synapse size within given synapse types, a two-way ANOVA was conducted. For this purpose, perforated and nonperforated synapses were classified into large and small by the total PSD length above or below the median (Fig. $1 F$ ). We found no significant interaction between synapse type and PSD size $\left(F_{(1,194)}=0.23, p=0.64\right)$. Furthermore, the main effect of synapse type, but not the PSD size, was statistically significant $\left(F_{(1,194)}=241.70, p<0.01\right.$ for synapse type; $F_{(1,194)}=2.62, p=$ 0.11 for PSD size). Therefore, the perforated type of PSD configuration is strongly associated with higher AMPAR density at SCC synapses on pyramidal cells.

In the CA1 stratum radiatum, SCC synapses on GABAergic interneurons also display a wide variability in immunogold labeling for AMPARs (Nusser et al., 1998). In our preliminary experiments, dendritic shafts decorated with numerous asymmetrical synapses invariably displayed prominent immunogold labeling for AMPARs, whereas those with sparse innervation exhibited low to moderate immunolabeling. Because dense SCC innervation on dendritic shafts is one of the hallmarks of PV-positive interneurons (Baude et al., 1995; Gulyás et al., 1999), and PVpositive and $\mathrm{PV}$-negative dendrites were clearly distinguished by the density of PV-immunolabeling (Fig. 1I), we used doublelabeling postembedding EM for PV (large particles) and AMPARs (small particles) (Fig. 1G,H,J,K). We found that immunogold particles were observed on all asymmetrical synapses on PV-positive and PV-negative dendritic shafts (28 of 28 PV synapses; 20 of 20 non-PV synapses) and that immunogold labeling was clearly higher at PV synapses (Fig. 1G,H) than at non-PV synapses (Fig. $1 J, K$ ). The mean density of AMPAR labeling was 3 

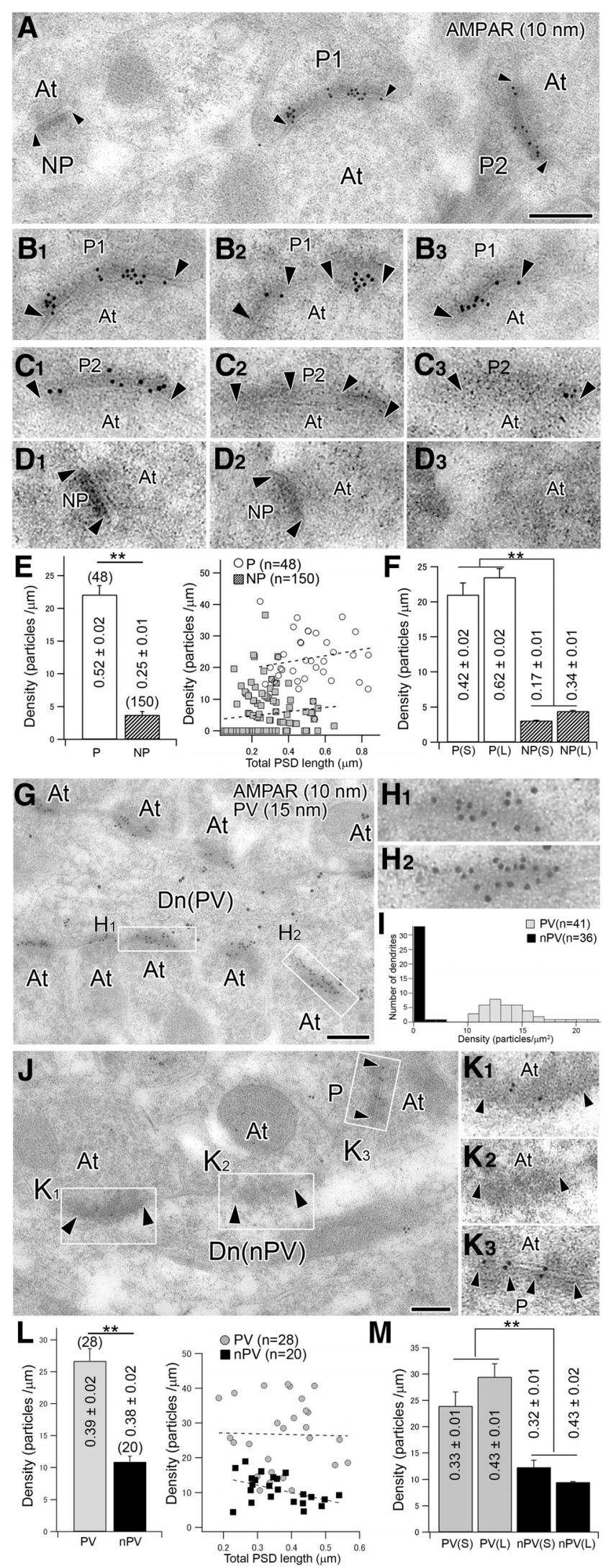

M

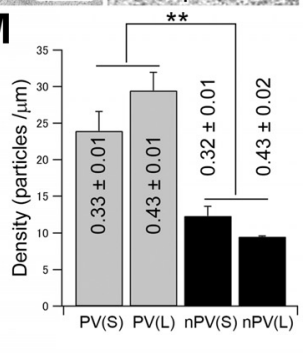

Figure 1. SCC synapses loaded with high- or low-density AMPARs in hippocampal CA1 pyramidal cells and interneurons. Pan-AMPAR antibody was used to evaluate AMPAR labeling density in Figure 1. A-D, Postembedding immunogold EM for AMPARs showing high-density labeling at perforated synapses (P1 and P2) and low-density labeling at nonperforated synapses (NP). Three asymmetrical synapses on pyramidal cell spines in $\boldsymbol{A}$ are enlarged as three times higher at PV synapses than at non-PV synapses (Fig. $1 L$, left; $p<0.01, U$ test). No significant difference in the total PSD length was observed between PV and non-PV synapses (0.39 \pm $0.02 \mu \mathrm{m}$ and $0.38 \pm 0.02 \mu \mathrm{m}$ from PV and non-PV synapses, respectively; $p=0.78, U$ test). When the density of AMPAR labeling at individual synapses was plotted as a function of the total PSD length (Fig. $1 L$, right), the correlation between the two parameters was not significant at PV synapses $(r=-0.023, p=$ $0.91)$, whereas there was a weak negative correlation at non-PV synapses $(r=-0.46, p<0.05)$. This expression was further confirmed by classifying PV and non-PV synapses into large or small ones by the total PSD length above or below the median (Fig. $1 M)$. A two-way ANOVA revealed no significant interaction between synapse type and PSD size $\left(F_{(1,44)}=2.30, p=0.14\right)$. Furthermore, the main effect of synapse type, but not the PSD size, was statistically significant $\left(F_{(1,44)}=45.74, p<0.01\right.$ for synapse type; $F_{(1,44)}=0.39, p=0.54$ for PSD size). Therefore, the target interneuron type is strongly associated with different AMPAR densities at SCC synapses on interneurons.

Together, these results suggest that AMPAR density varies significantly across SCC synapses; that is, between perforated and nonperforated types of SCC synapses on pyramidal cells and between SCC synapses on PV and non-PV interneurons.

\section{Composition of GluA subunits}

The disparity in AMPAR expression at SCC synapses was further investigated using subunit-specific GluA antibodies, the specificity of which was confirmed by blank immunohistochemical labeling in the brains and synapses of corresponding GluA-KO mice (Tables 2, 3; Yamasaki et al., 2011). Immunofluorescence using paraffin sections revealed two distinct patterns of labeling in the hippocampal CA1 area: fine punctate labeling in the neuropil and coarse peridendritic labeling of putative interneurons (Fig. 2A-H). Triple immunofluorescence clarified that punctate neuropil labeling was found for GluA1, GluA2, and GluA3 (Fig.

consecutive images in $\boldsymbol{B}-\boldsymbol{D}$. Arrowhead pairs indicate the edge of synapses. At, Axon terminals. $\boldsymbol{E}$, Mean AMPAR labeling density at perforated ( $\mathrm{P}$, open column) and nonperforated (NP, dashed column) synapses (right) and plots of AMPAR labeling density (per $\mu \mathrm{m}$ of the total PSD length, ordinate) and the total PSD length ( $\mu \mathrm{m}$, abscissa) at individual perforated (open circles) and nonperforated (dashed squares) synapses measured from serial sections (right). ${ }^{* *} p<0.01, U$ test. Dashed lines are linear regression fits to the data. $\boldsymbol{F}$, Comparison of the mean AMPAR labeling density in small (S) and large (L) perforated (open columns) and nonperforated (dashed columns) synapses. Comparison of the means by a two-way ANOVA shows that the main effect of synapse type, but not the PSD size, is statistically significant $\left({ }^{* *} p<0.01\right.$ and $p=$ 0.54, respectively). $\boldsymbol{G}, \boldsymbol{H}, \boldsymbol{J}, \boldsymbol{K}$, Double-labeling postembedding immunogold EM for AMPAR $(\phi=10 \mathrm{~nm})$ and parvalbumin (PV, $15 \mathrm{~nm})$ showing high-density AMPAR labeling at dendritic shaft synapses on PV-positive interneurons [Dn(PV), PV synapses] and low-density labeling at those on PV-negative interneurons [Dn(nPV); non-PV synapses]. Boxed regions in $\mathbf{G}$ and $\boldsymbol{J}$ are enlarged and shown in $\boldsymbol{H}$ and $\boldsymbol{K}$. I, Summary histogram showing the distribution of averaged labeling density in each dendritic profile obtained from three to four consecutive sections. Note that the density of PV-immunolabeling in PV-positive (PV, gray columns) and PV-negative (nPV, black columns) dendrites in the present study display a clear bimodal distribution. L, Mean density of AMPAR labeling at PV (PV, gray column) and non-PV (nPV, black column) synapses (left) and plots of AMPAR labeling density (ordinate) and the total PSD length (abscissa) at individual PV (gray circles) and non-PV (black squares) synapses measured from serial sections (right). ${ }^{* *} p<0.01, U$ test. Dashed lines are linear regression fits to the data. $\boldsymbol{M}$, Comparison of the mean AMPAR labeling density in small (S) and large (L) PV (gray columns) and non-PV (black columns) synapses. Comparison of the means by a two-way ANOVA shows that the main effect of synapse type, but not the PSD size, is statistically significant $\left({ }^{* *} p<0.01\right.$ and $p=0.11$, respectively). A total of 246 synapses were reconstructed from 81 sections. The numbers of synapses or dendritic profiles examined and the total length of PSD (mean \pm SEM) are indicated in parentheses or in/on the bar, respectively. Error bars indicate SEM. Scale bars, $200 \mathrm{~nm}$. 
GluA1
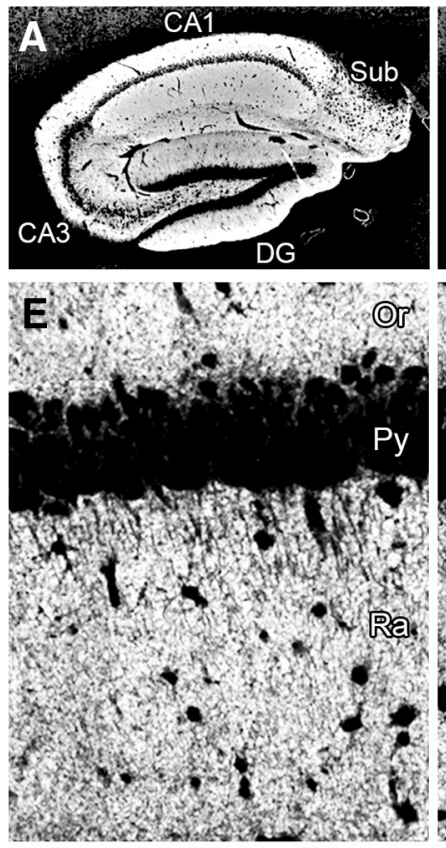

GluA2
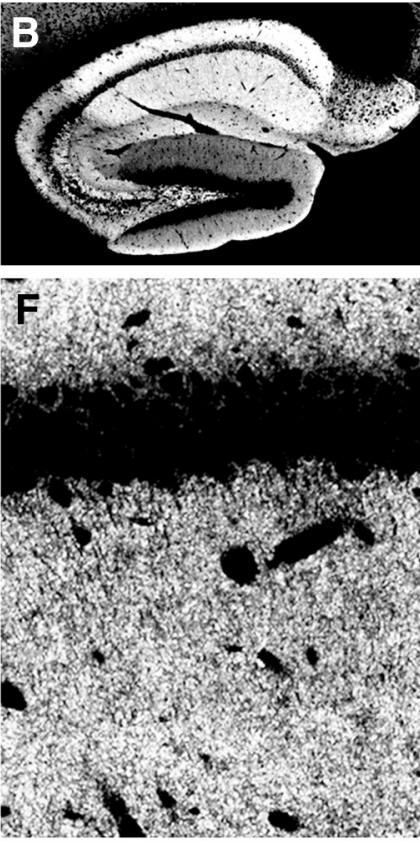

GluA3
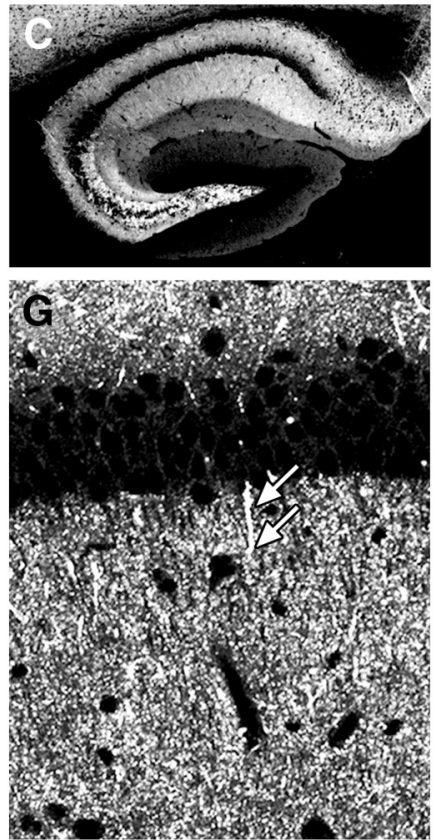

GluA4
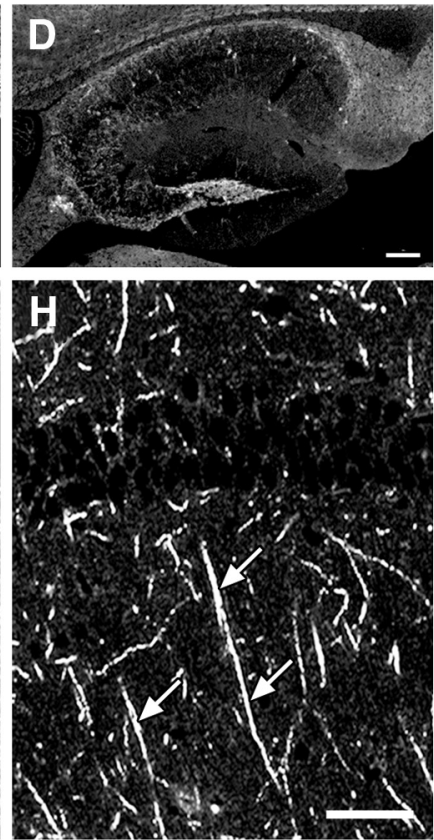
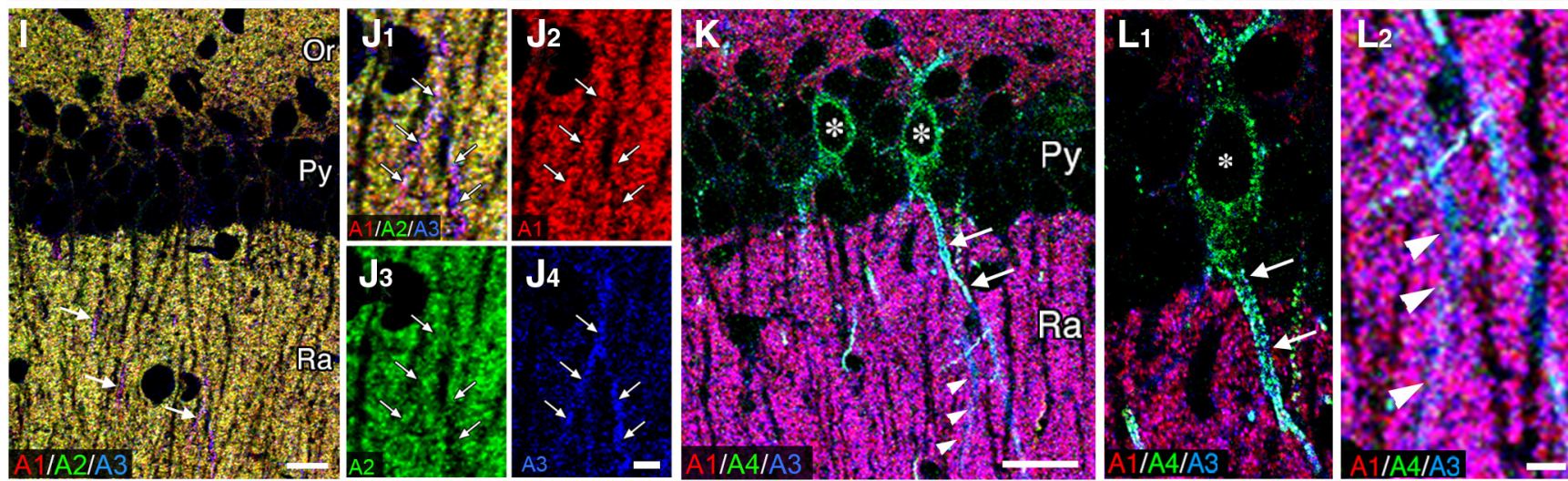

Figure 2. Immunofluorescence labeling for four GluA subunits. $\boldsymbol{A}-\boldsymbol{D}$, Overall labeling patterns in the hippocampus. $\boldsymbol{E}-\boldsymbol{H}$, Magnified images of the CA1 area. Arrows indicate peridendritic labeling of putative interneurons for GluA3 and GluA4. Intense fine punctate labeling in the neuropil for GluA1 masks peridendritic labeling of putative interneurons. $I, J$, Triple immunofluorescence for GluA1 (red), GluA2 (green), and GluA3 (blue) in the CA1 area. Note that neuropil puncta are labeled intensely for GluA1 and GluA2 and low to moderately for GluA3, yielding homogeneous whitish-yellow colors. Peridendritic labeling of putative interneurons is also seen for GluA1 and GluA3, but not GluA2 (J, arrows). $\boldsymbol{K}, \boldsymbol{L}$, Triple immunofluorescence for GluA1 (red), GluA3 (blue), and GluA4 (green) in the CA1 area. Note that peridendritic labeling yields white (GluA1+/GluA3+/GluA4+; arrows) to light-blue (GluA3+/GluA4+; arrowheads) colors. DG, Dentate gyrus; Or, stratum oriens; Py, pyramidal cell layer; Ra, stratum radiatum; Sub, subiculum. Scale bars: $\boldsymbol{A}-\boldsymbol{D}$ (in $\boldsymbol{D}$ ), $200 \mu \mathrm{m} ; \boldsymbol{E}-\boldsymbol{H}$ (in $\boldsymbol{H}$ ), $20 \mu \mathrm{m} ; \boldsymbol{I}, \boldsymbol{K}, 20 \mu \mathrm{m} ; \boldsymbol{J}, \boldsymbol{L}, 10 \mu \mathrm{m}$.

$2 I, J)$, whereas peridendritic labeling was evident for GluA1, GluA3, and GluA4, with occasional labeling for GluA2 (Fig. $2 K, L)$.

We then examined the density of GluA labeling at given types of SCC synapses (Fig. 3). Consistent with the results gained using the pan-AMPAR antibody, the labeling density was significantly higher at perforated synapses than at nonperforated synapses for GluA1, GluA2, and GluA3 (Fig. 3I-K, columns and left axis; $p<$ 0.01 ; $U$ test). Similarly, it was significantly higher at PV synapses than at non-PV synapses for all four subunits (Fig. 3I- $L$, columns and left axis; $p<0.05$ and $p<0.01$ for GluA1 and GluA2-GluA4, respectively, $U$ test). Because there was a considerable difference in the density of AMPAR labeling between the four synapse types (Fig. 1E,L), we standardized the expression levels of GluA subunits by calculating an expression index. This was obtained by dividing the labeling density using GluA subunit antibodies by that using the pan-AMPAR antibody at the corresponding syn- apse types (Fig. 3I-L, red dots and right axis). We found no significant differences between perforated and nonperforated synapses in the expression index for GluA1, GluA2, GluA3, or GluA4 ( $p=0.44,0.32,0.25$, and 0.66 , respectively, $U$ test). Similarly, there were no significant differences between PV and non-PV synapses for GluA1, GluA2, and GluA3 ( $p=0.88,0.21$, and 0.29 , respectively, $U$ test). In contrast, the expression index for GluA4 was significantly higher at PV synapses than at non-PV synapses ( $p<0.01, U$ test). These results suggest that the subunit composition at perforated and nonperforated synapses on pyramidal cells is quite similar, whereas it is different between PV and non-PV interneurons. Therefore, the composition of GluA subunits appears to undergo target cell type-dependent regulation between pyramidal cells and interneurons and also among interneuron populations.

Target cell type-dependent regulation was further examined by FISH. FISH using antisense cRNA probes for each GluA sub- 

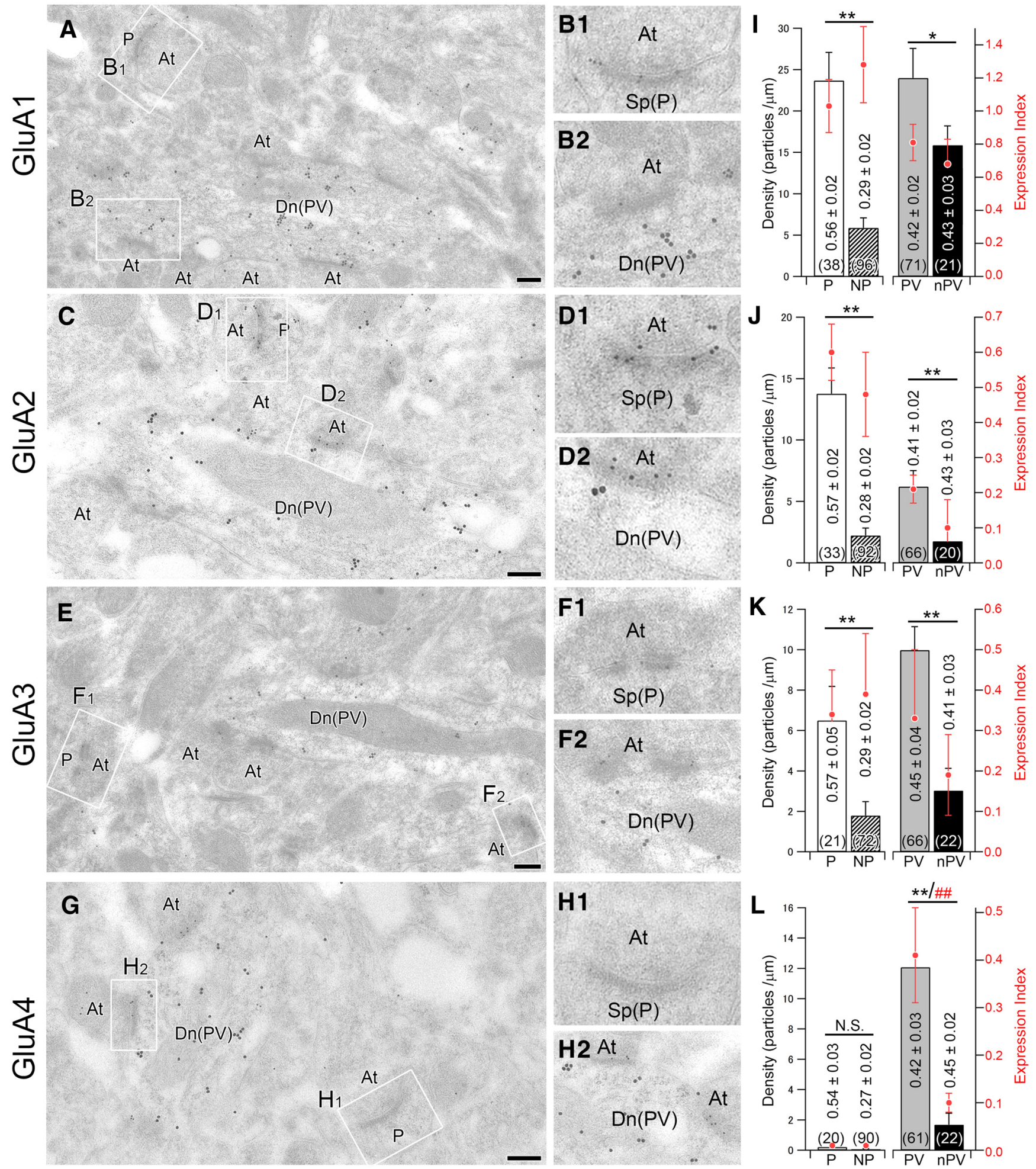

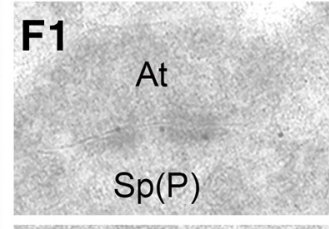

\section{F2 At}
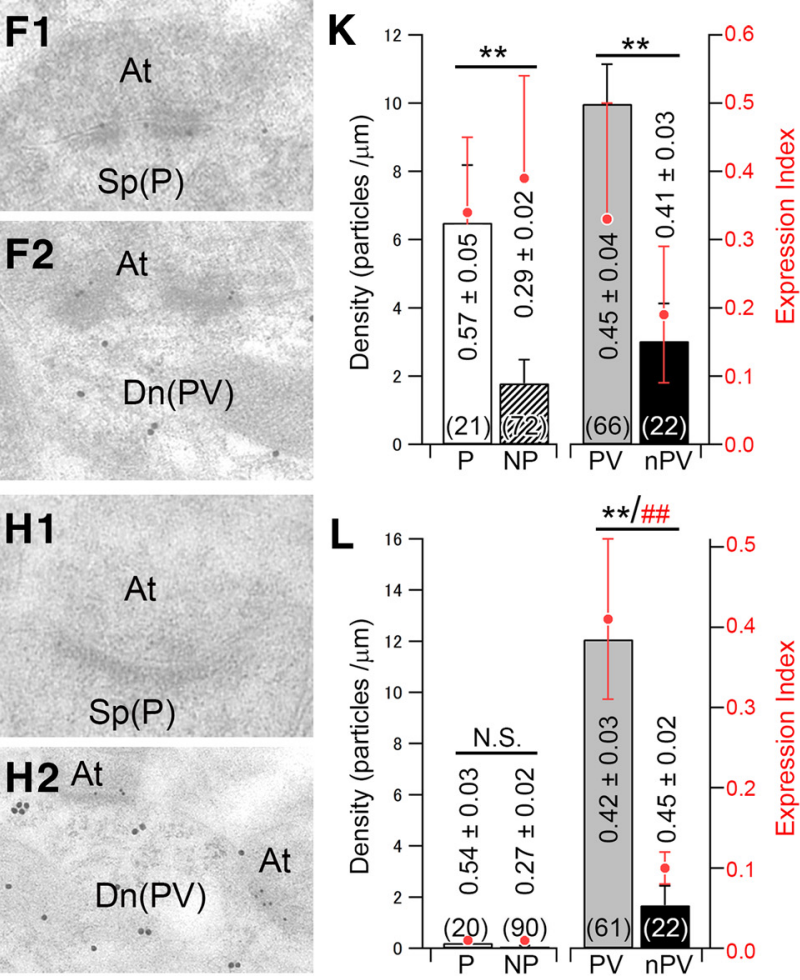

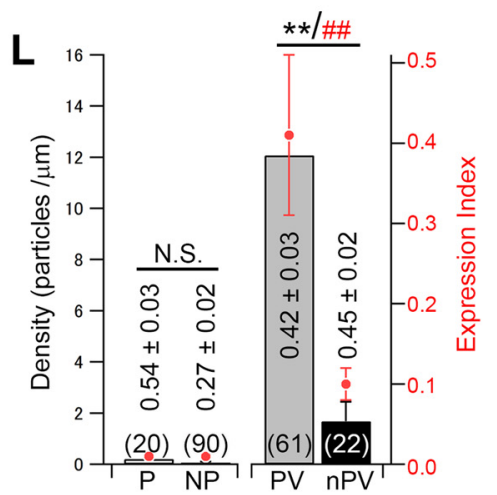

Figure 3. The density and composition of four GluA subunits at four types of SCC synapses. $\boldsymbol{A}-\boldsymbol{H}$, Double-labeling postembedding immunogold EM for each GluA subunit ( $\boldsymbol{\phi}=10 \mathrm{~nm}$ ) and PV (15 nm). Dn(nPV), shaft dendrite forming non-PV synapses; Dn(PV), shaft dendrite forming PV synapses; Sp(NP), spine forming nonperforated synapse; Sp(P), spine forming perforated synapse. For other abbreviations, see Figure 1. I-L, Columns, Left axis, Mean labeling density of GluA subunits per unit PSD length ( $\mu \mathrm{m}$ ) at given synapse types measured from serial sections. ${ }^{* *} p<0.01,{ }^{*} p<$ 0.05; N.S., not significant; differences in the labeling density between perforated and nonperforated synapses and between PV and non-PV synapses, $U$ test. Note significantly higher labeling densities at perforated synapses (P) than at nonperforated synapses (NP) for GluA1, GluA2, and GluA3, and also at PV synapses (PV) than at non-PV synapses (nPV) for all four subunits. $I-L$, Right axis, Dots, Mean expression index of GluA subunits as calculated by dividing the labeling density using GluA subunit antibodies by that using pan-AMPAR antibody. \#\# $<0.01$, \#p < 0.05 ; differences in the expression index between perforated and nonperforated synapses and between PV and non-PV synapses; $U$ test. Note no significant differences between perforated (P) and nonperforated (NP) synapses in the expression index for GluA1, GluA2, or GluA3. In contrast, the expression index tends to be substantially higher at PV synapses than at non-PV synapses for all four GluA subunits, particularly GluA4. A total of 226, 211, 181, and 191 synapses were reconstructed from 60, 72, 65, and 60 sections for GluA1, GluA2, GluA3, and GluA4 analysis, respectively. The numbers of synapses examined and the total PSD length (mean \pm SEM) are indicated in parentheses and in/on the bar, respectively. Error bars indicate SEM. Scale bars, $200 \mathrm{~nm}$. 

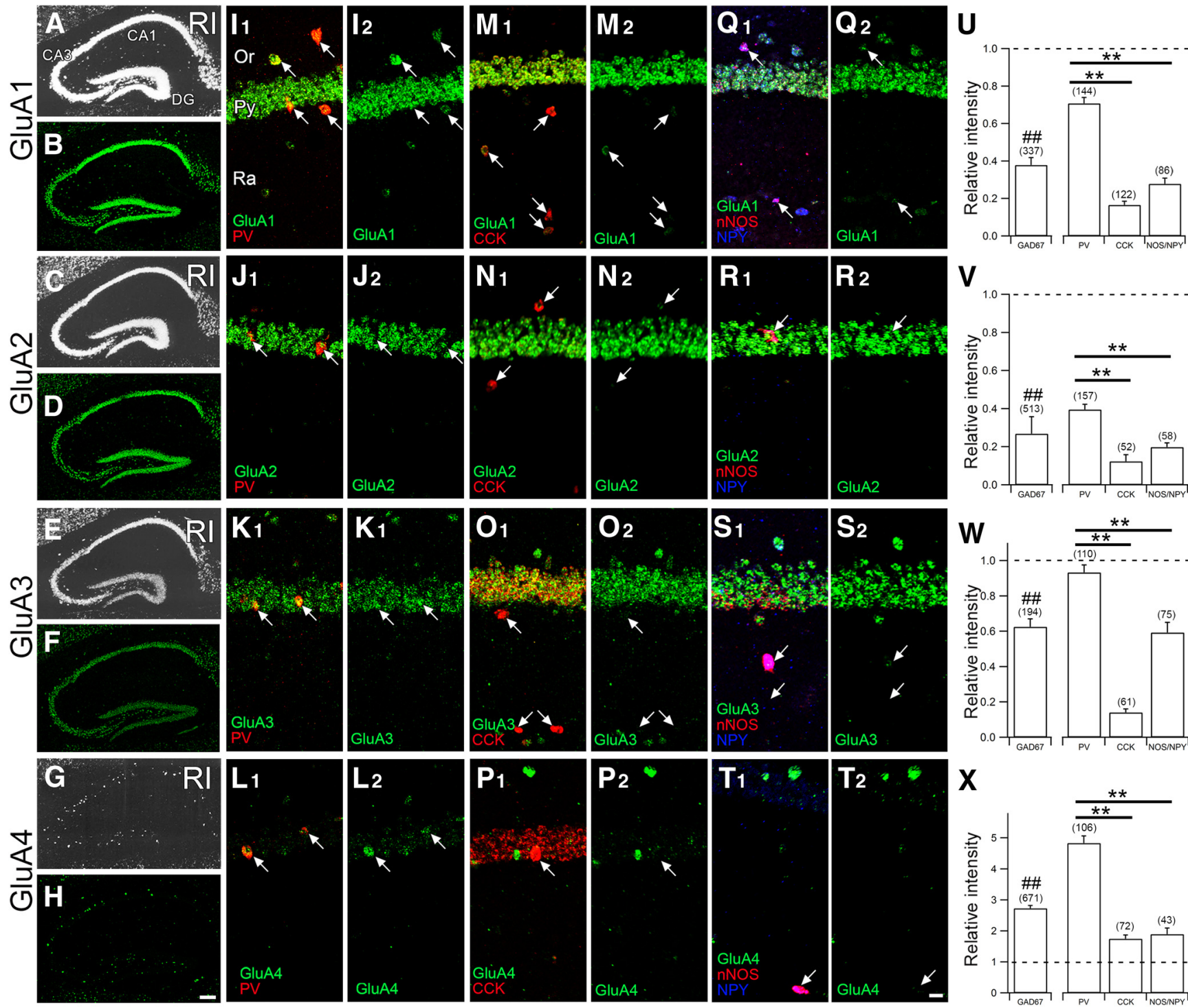

Figure 4. In situ hybridization showing the neuron-type-dependent expression of four GluA subunits in CA1 pyramidal cells and interneurons. $\boldsymbol{A}-\boldsymbol{H}$, Single-labeling in situ hybridization in the hippocampus using isotopic oligonucleotide probes $(\boldsymbol{A}, \boldsymbol{C}, \boldsymbol{E}, \boldsymbol{G})$ and nonisotopic riboprobes $(\boldsymbol{B}, \boldsymbol{D}, \boldsymbol{F}, \boldsymbol{H}) . \boldsymbol{I}-\boldsymbol{T}$, Double- or triple-labeling FISH showing distinct GluA subunit expressions in PV-positive $(\boldsymbol{I}-\boldsymbol{L})$, CCK-positive $(\boldsymbol{M}-\boldsymbol{P})$, and nNOS/NPY-positive $(\boldsymbol{Q}-\boldsymbol{T})$ interneurons. $\boldsymbol{U}-\boldsymbol{X}$, Mean relative fluorescence intensity of each GluA subunit mRNA in GABAergic interneurons expressing GAD67 mRNA and three major subtypes of interneurons. The intensity in each interneuron type is normalized to that in CA1 pyramidal cells (dashed lines).\#\#p $<0.01$, comparison between GAD67-expressing cells and pyramidal cells, $U$ test. ${ }^{* *} p<0.01$, comparison with PV-positive interneurons; KW test with post hoc Sheffe's procedure. Note higher expression levels of all four GluA subunits in PV-positive interneurons among the three interneuron subpopulations. The numbers of neurons examined are indicated in parentheses. Error bars indicate SEM. Scale bars: $\boldsymbol{A}-\boldsymbol{H}$ (in $\boldsymbol{H}$ ), $200 \mu \mathrm{m} ; \boldsymbol{I}-\boldsymbol{T}$ (in $T), 20 \mu \mathrm{m}$.

unit yielded characteristic expression patterns in the hippocampus (Fig. $4 B, D, F, H$ ), which were similar to those obtained by radiolabeled antisense oligonucleotide probes (Fig. $4 A, C, E, G$ ). In double- or triple-FISH, we identified pyramidal cells as cells lacking GAD67 mRNA expression in the pyramidal cell layer, whereas interneurons were identified by expression of GAD67 mRNA and respective interneuron markers (Fig. $4 I-T$ ). Pyramidal cells strongly expressed GluA1, GluA2, and GluA3 mRNAs, but were quite low in GluA4 mRNA. To compare the expression levels of the respective GluA mRNAs between GAD67-expressing interneurons and pyramidal cells, and also among three major subpopulations of interneurons, the PV-, CCK-, and nNOS/ NPY-expressing interneurons (Somogyi and Klausberger, 2005; Fuentealba et al., 2008), we normalized the fluorescent intensity in each type of interneurons to the averaged intensity in pyramidal cells (Fig. $4 U-X$ ). Compared with pyramidal cells (dashed lines), the mean intensity in GAD67-expressing interneurons was significantly lower for GluA1, GluA2, and GluA3 mRNAs and significantly higher for GluA4 mRNA (Fig. $4 U-X ; p<0.01$ each, $U$ test). Among the three interneuron subpopulations, PVpositive interneurons showed significantly higher levels of all four GluA subunits compared with other interneurons expressing CCK or nNOS/NPY (Fig. $4 U-X ; p<0.01$ each, KW test followed by Sheffe's post hoc test). These expression properties support the target cell type-dependent composition of GluA subunits.

\section{Homogeneous density of PSD-95}

Retaining AMPARs at synapses requires specific interactions with membrane-associated guanylate kinases (MAGUKs) and TARPs (Schnell et al., 2002; Jackson and Nicoll, 2011b). Because PSD-95 is the most influential MAGUK for the synaptic expression of 

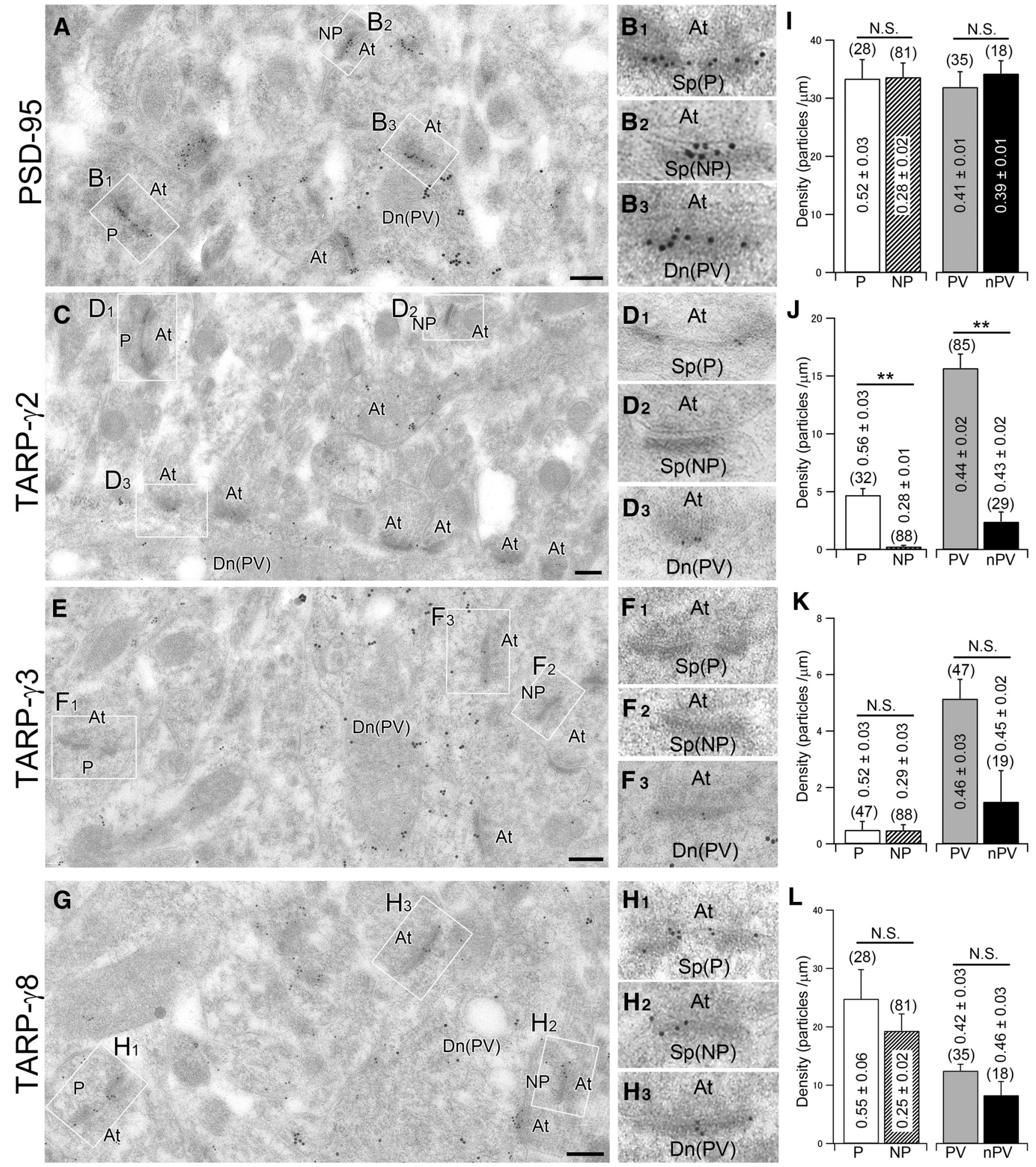

Figure 5. Homogeneous PSD-95 densities and heterogeneous TARP densities in four types of SCC synapses. $\boldsymbol{A}-\boldsymbol{H}$, Double-labeling postembedding immunogold EM for PV $(\boldsymbol{\phi}=15 \mathrm{~nm})$ and PSD-95 $(10 \mathrm{~nm} ; \boldsymbol{A}, \boldsymbol{B})$, TARP $\gamma-2(10 \mathrm{~nm} ; \boldsymbol{C}, \boldsymbol{D})$, TARP $\gamma-3(10 \mathrm{~nm} ; \boldsymbol{E}, \boldsymbol{F})$, or TARP $\gamma-8(10 \mathrm{~nm} ; \boldsymbol{G}, \boldsymbol{H})$. See abbreviations in Figures 1 and $3 . \boldsymbol{I}-\boldsymbol{L}$, Mean labeling density of PSD-95 (I), TARP $\gamma-2(\boldsymbol{J})$, TARP $\gamma-3(\boldsymbol{K})$, and TARP $\gamma-8(\boldsymbol{L})$ per unit PSD length $(\mu \mathrm{m})$ at individual synapse types measured from serial sections. ${ }^{* *} p<0.01$; N.S., not significant; differences in the labeling density between perforated and nonperforated synapses, and between PV and non-PV synapses; U test. A total of 162, 234, 201, and 162 synapses were reconstructed from 79, 65, 60, and 71 sections for PSD95, TARP $\gamma$-2, TARP $\gamma-3$, and TARP $\gamma-8$ analysis, respectively. The numbers of synapses examined and the total PSD length (mean \pm SEM) are indicated in parentheses and in/on the bar, respectively. Error bars indicate SEM. Scale bars, $200 \mathrm{~nm}$.

AMPARs in the hippocampus (El-Husseini et al., 2000; Béïque and Andrade, 2003; Huganir and Nicoll, 2013), we compared the density of PSD-95 labeling among SCC synapses (Fig. 5A,B). Immunogold labeling for PSD-95 was observed in all synapses analyzed from each type of SCC synapse. The density of PSD-95 labeling showed no significant differences between perforated and nonperforated synapses and between PV and non-PV synapses (Fig. 5I; $p=0.35$ and 0.18 , respectively, $U$ test). Further- 

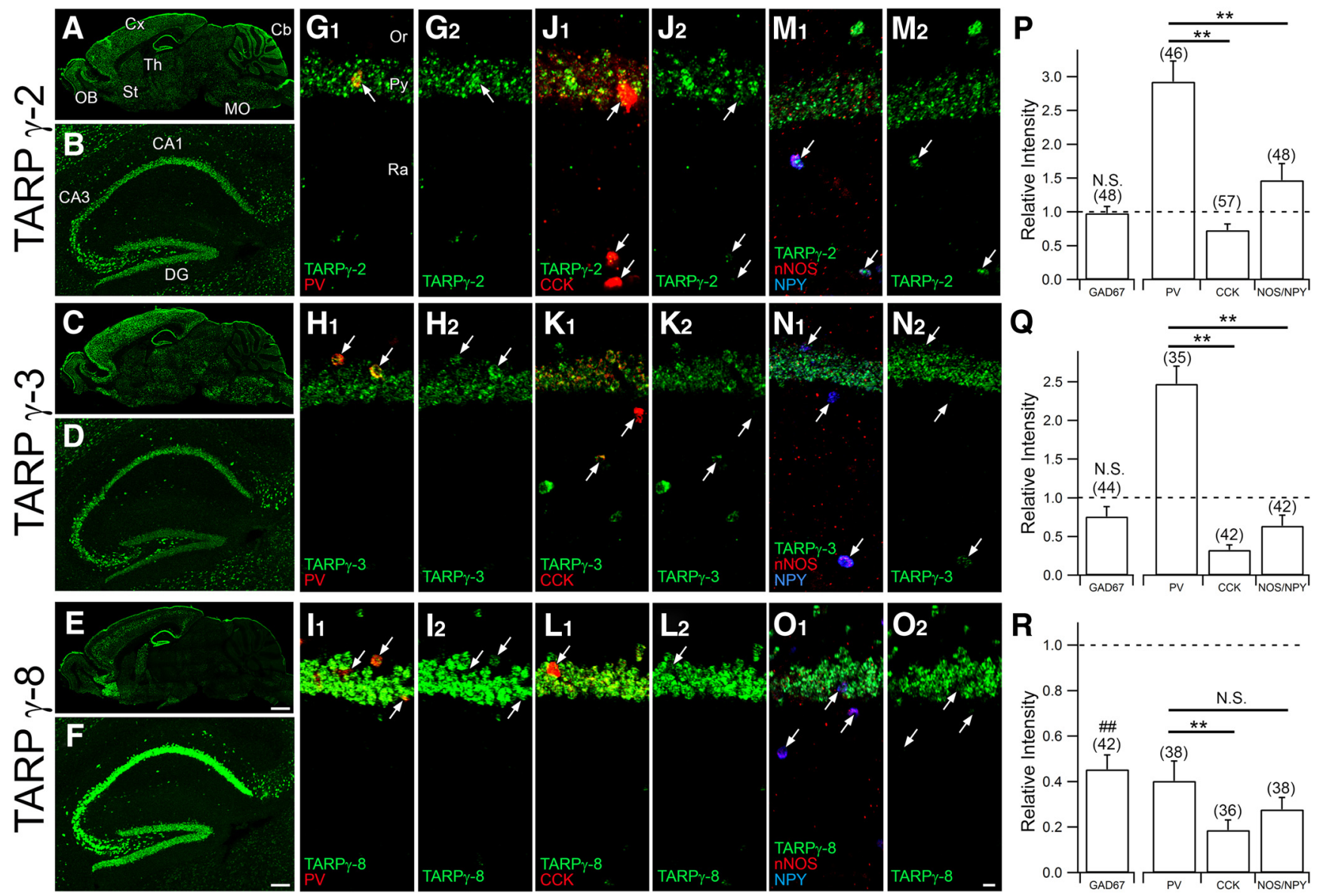

Figure 6. FISH showing neuron-type-dependent expression of TARP mRNAs in CA1 pyramidal cells and interneurons. $\boldsymbol{A}-\boldsymbol{F}$, Single-labeling FISH showing overall expression patterns of TARP $\gamma$-2 $(\boldsymbol{A}, \boldsymbol{B}), \operatorname{TARP} \gamma-3(\boldsymbol{C}, \boldsymbol{D})$, and TARP $\gamma-8(\boldsymbol{E}, \boldsymbol{F}) \mathrm{mRNAs}$ in the brain $(\boldsymbol{A}, \boldsymbol{C}, \boldsymbol{E})$ and hippocampus $(\boldsymbol{B}, \boldsymbol{D}, \boldsymbol{F}) . \mathbf{G}-\mathbf{0}$, Double- or triple-labeling FISH showing distinct neuronal expressions of TARP isoforms in PV-positive (arrows in $\mathbf{G}-\boldsymbol{l}$ ), CCK-positive (arrows in $\boldsymbol{J}-\boldsymbol{L}$ ), and nNOS/NPY-positive (arrows in $\boldsymbol{M}-\boldsymbol{0}$ ) interneurons. $\boldsymbol{P}-\boldsymbol{R}$, Mean relative fluorescence intensity of TARP $\gamma$-2 (P), TARP $\gamma$-3 ( $\boldsymbol{Q}$ ), and TARP $\gamma-8(\boldsymbol{R})$ mRNAs in GABAergic interneurons expressing GAD67 mRNA and three major subtypes of interneurons. The intensity in each interneuron type is normalized to that in CA1 pyramidal cells (dashed lines). Note that PV-positive interneurons express higher levels of TARP $\gamma-2$ and $\gamma$-3 mRNAs than the other neuron types, whereas pyramidal cells express higher levels of TARP $\gamma-8 \mathrm{mRNA}$ than interneurons. The number of cells examined is indicated in parentheses. \#\#p $<0.01$; N.S., not significant; comparison between GAD67-expressing cells and pyramidal cells, Utest. ${ }^{* *} p<0.01$; N.S., not significant; comparison with PV-positive interneurons; KW test with post hoc Sheffe's procedure. Error bars indicate SEM. Scale bars: $\boldsymbol{A}, \boldsymbol{C}, \boldsymbol{E}$ (in $\boldsymbol{E}$ ), $1 \mathrm{~mm} ; \boldsymbol{B}, \boldsymbol{D}, \boldsymbol{F}$ (in $\boldsymbol{F}$ ), $200 \mu \mathrm{m} ; \boldsymbol{G}-\mathbf{O}$ (in $\mathbf{0}$ ), $20 \mu \mathrm{m}$.

more, there were no significant differences among all four synapse types ( $p=0.36, \mathrm{KW}$ test). Therefore, despite a large disparity in AMPAR labeling, the density of PSD-95 labeling is homogeneous across SCC synapses.

\section{Heterogeneous density of TARPs}

Among four classical or type-I TARPs with high sequence homology, TARP $\gamma$-2, TARP $\gamma-3$, and TARP $\gamma$-8 are transcribed in hippocampal neurons (Tomita et al., 2003; Fukaya et al., 2005). We characterized their cellular expressions by FISH (Fig. 6A-O). Pyramidal cells were labeled for the three TARPs, with the highest fluorescent intensity for TARP $\gamma-8$ mRNA and the lowest for TARP $\gamma-3$ mRNA. The relative intensity in interneurons was also calculated by defining the mean fluorescence intensity in pyramidal cells (i.e., GAD67 mRNA-negative cells in the pyramidal cell layer) as 1.0 (dashed lines in Fig. $6 P-R$ ). The mean relative intensity of TARP $\gamma$-2 and TARP $\gamma$-3 mRNAs in PV-positive interneurons was several times higher than that in CCK-positive or nNOS/NPY-positive interneurons (Fig. 6P, Q; $p<0.01$ each, KW test followed by Sheffe's post hoc test). In contrast, the mean relative intensity of TARP $\gamma-8$ mRNA was twofold to threefold higher in pyramidal cells than in GAD67-expressing interneu- rons (Fig. $6 R$, left, $p<0.01, U$ test). These findings indicate the prominent expression of TARP $\gamma-2$ and TARP $\gamma$ - 3 in PV-positive interneurons and of TARP $\gamma-8$ in pyramidal cells at the transcription level. High expression of TARP $\gamma$ - 2 in PV-positive interneurons has also been reported in the neocortex (Maheshwari et al., 2013).

Consistent with this expression pattern, immunofluorescence labeling using TARP isoform-specific antibodies, the specificity of which was confirmed at the light microscopic level by blank labeling in the corresponding $\mathrm{KO}$ mice (Fig. $7 A-C$ ), visualized predominant peridendritic labeling of putative interneurons for TARP $\gamma$ - 2 and TARP $\gamma$-3, and predominant punctate labeling in the neuropils for TARP $\gamma-8$ in the hippocampal CA1 area (Fig. $7 D-F)$.

Next, we analyzed the density of synaptic TARP labeling using TARP isoform-specific antibodies, the specificity of which was confirmed at the EM level using the corresponding $\mathrm{KO}$ mice (Tables 2, 3). TARP $\gamma$-2 labeling was prominent at PV synapses and moderate at perforated synapses, showing significant differences between perforated and nonperforated synapses and between PV and non-PV synapses (Fig. 5C,D, J; $p<0.01$ each, $U$ test). TARP $\gamma$-3 labeling was only prominent at PV synapses, but 
TARP $\gamma-2$
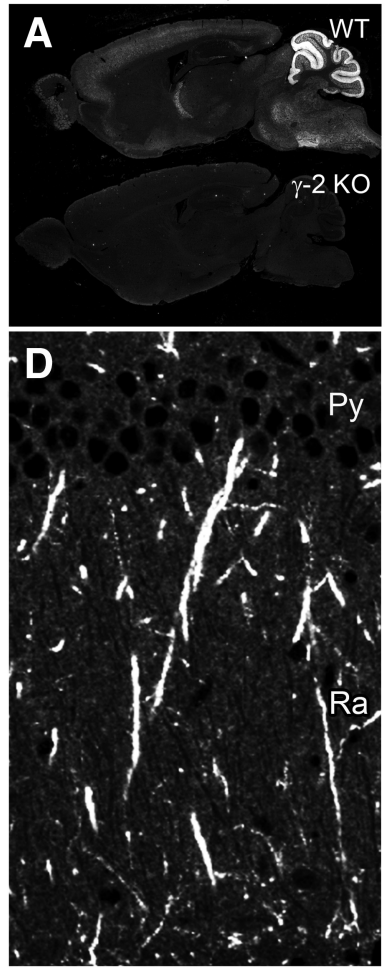

TARP $\gamma-3$
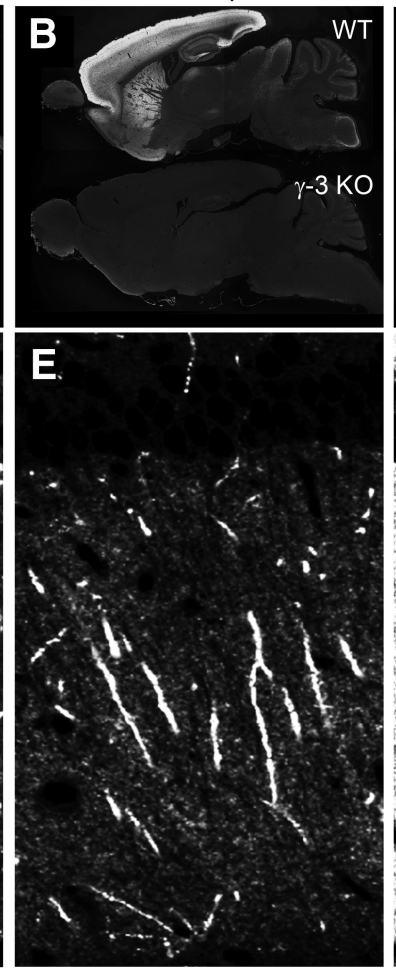

TARP $\gamma-8$
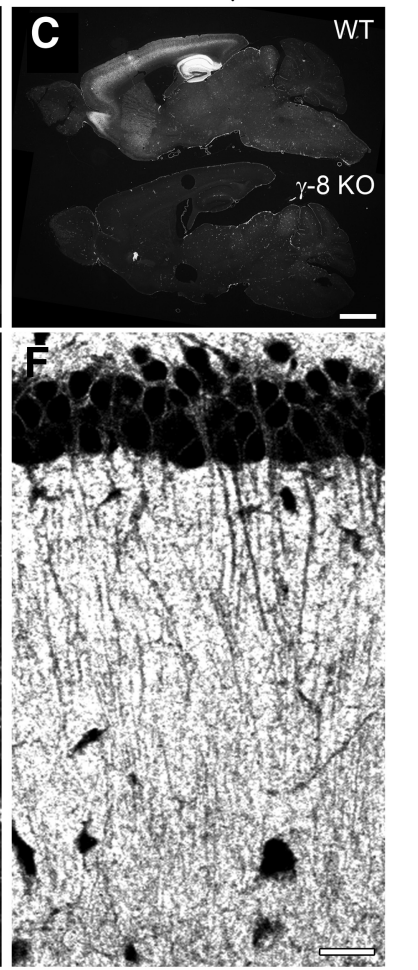

Figure 7. Immunofluorescence showing specific and distinct TARP labeling in the hippocampal CA1 area. $\boldsymbol{A}-\boldsymbol{C}$, Immunofluorescence for TARP $\gamma$-2, TARP $\gamma$-3, and TARP $\gamma-8$ in parasagittal paraffin sections in WT (top) and the corresponding TARP-K0 (bottom) mice. Note almost blank immunolabelings in the corresponding TARP-KO brains. $\boldsymbol{D}-\boldsymbol{F}$, Coarse peridendritic labeling of putative interneurons is conspicuous for TARP $\gamma$-2 and TARP $\gamma$-3, whereas intense neuropil punctate labeling is evident for TARP $\gamma-8$ in the CA1 area. Scale bars: $\boldsymbol{A}-\boldsymbol{C}$ (in $\boldsymbol{C}), 1 \mathrm{~mm}: \boldsymbol{D}-\boldsymbol{F}$ (in $\boldsymbol{F}), 20 \mu \mathrm{m}$.

there was no significant difference in the labeling density (Fig. $5 E, F, K$, right; $p=0.25, U$ test). In contrast, TARP $\gamma$ - 8 was richly expressed at various SCC synapses, showing no significant differences between perforated and nonperforated synapses and between PV and non-PV synapses (Fig. 5G, H, $L ; p=0.13$ and 0.55 , respectively, $U$ test). Therefore, synaptic expression of TARPs is differentially regulated among the four types of SCC synapses. The disparity in synaptic AMPAR labeling in pyramidal cells (i.e., perforated synapse $>$ nonperforated synapse) and in interneurons (i.e., PV synapse $>$ non-PV synapse) was reproduced for TARP $\gamma$-2, but not for TARP $\gamma$-3 or $\gamma$-8. It should also be noted that TARP $\gamma-8$ is the only major TARP expressed at nonperforated synapses.

\section{Skewed AMPAR allocation requires TARP $\gamma-2$}

To pursue the role of TARPs in the disparity of AMPAR densities at SCC synapses, we analyzed TARP-KO mice. Serial conventional EM analysis showed that, compared with WT control mice, the fraction of perforated synapses in the total SCC synapses on dendritic spines was not significantly different in TARP $\gamma$-2-KO $(8.2 \pm 0.85 \%)$, TARP $\gamma$-3-KO $(8.3 \pm 1.34 \%)$, or TARP $\gamma$ - 8 -KO mice $(6.9 \pm 0.85 \%)$ ( $n=6$ fields of view from 3 mice; $p=0.17$, KW test).

Pan-AMPAR antibody was applied to parasagittal paraffin sections of WT and TARP-KO brains, which had been mounted on the same glass slides for immunofluorescence incubations under the same conditions. We found differential alterations in AMPAR labeling patterns among TARP-KO mice (Fig. 8A-L). Compared with control mice (Fig. $8 A, E, I$ ), the overall intensity of AMPAR labeling in the hippocampus was reduced mildly in
TARP $\gamma$-2-KO mice (Fig. $8 B$ ) and severely in TARP $\gamma$-8-KO mice (Fig. $8 \mathrm{~J}$ ). No discernible changes were observed in TARP $\gamma$-3-KO mice (Fig. 8F). The striking reduction of AMPAR labeling in TARP $\gamma$-8-KO hippocampi is consistent with previous reports (Rouach et al., 2005; Fukaya et al., 2006). At a higher magnification, peridendritic labeling of putative interneurons was combined with punctate neuropil labeling in the stratum radiatum of control mice (Fig. $8 C, G, K$ ). In TARP $\gamma$-2-KO mice, reduced signal intensity was moderate for punctate neuropil labeling and severe for peridendritic labeling (Fig. 8D). In comparison, a marked reduction was observed for punctate neuropil labeling in TARP $\gamma-8$-KO mice, leaving peridendritic labeling and a few bright neuropil puncta intact (Fig. $8 L$ ).

We then measured the density of immunogold labeling for AMPARs at four types of SCC synapses in these TARP-KO mice (Fig. 8M-U). The normalized expression level was calculated as the percentage relative to the mean density of AMPAR labeling at the corresponding synapse types in control mice (Fig. $8 \mathrm{~V}-$ $X)$. The disparity in synaptic labeling for AMPARs in control mice (Fig. $1 E, L$ ) was disrupted in TARP $\gamma$-2-KO mice, showing almost comparable densities between perforated and nonperforated synapses and between PV and non-PV synapses (Fig. $8 S ; p=0.21$ and 0.92 , respectively, $U$ test). This was due to a marked and significant reduction at perforated and PV synapses to $33.0 \pm 8.5 \%$ and $30.5 \pm 4.1 \%$, respectively $(p<0.01$ each, $U$ test). No changes were observed in the density and normalized expression level of AMPARs in TARP $\gamma-3-\mathrm{KO}$ mice (Fig. 8T, $W$; $p<0.01$ each, $U$ test). In TARP $\gamma$-8-KO mice, the disparity in synaptic labeling was largely preserved (Fig. $8 U ; p<0.01$ each, $U$ test), but the density and normalized expression level of AMPARs were severely reduced at nonperforated synapses $(17.7 \pm 5.0 \%$; Fig. $8 X, p<0.01, U$ test). A mild reduction was also found at perforated synapses in TARP $\gamma-8 \mathrm{KO}$ mice $(p<0.01$ each, $U$ test). These results suggest that TARP $\gamma$ - 2 plays a key role in the high-density expression of AMPARs at perforated and PV synapse, and thereby constructs the framework of heterogeneous AMPAR expression among SCC synapses. TARP $\gamma-8$ plays a critical role in AMPAR expression at nonperforated synapses, the most numerous synapses in the CA1 stratum radiatum.

\section{TARPs do not show GluA subunit preference}

Using subunit-specific GluA antibodies, we investigated whether particular GluA subunits were selectively affected in TARP $\gamma$-2-KO and TARP $\gamma$-8-KO mice (Fig. 9). In TARP $\gamma$-2-KO mice, severe reductions were observed for GluA1, GluA2, and GluA3 at perforated synapses (Fig. 9A, left; $p<0.01$ each, $U$ test) and for all four GluA subunits at PV synapses (Fig. 9C, left; $p<0.01$ each, $U$ test), showing similar extents of reductions among GluA subunits ( $p=0.56$ and 0.41 , respectively, $\mathrm{KW}$ test). Likewise, in TARP $\gamma$-8-KO mice, GluA1, GluA2, and GluA3 were mildly or severely reduced at perforated and nonperforated synapses, respectively 

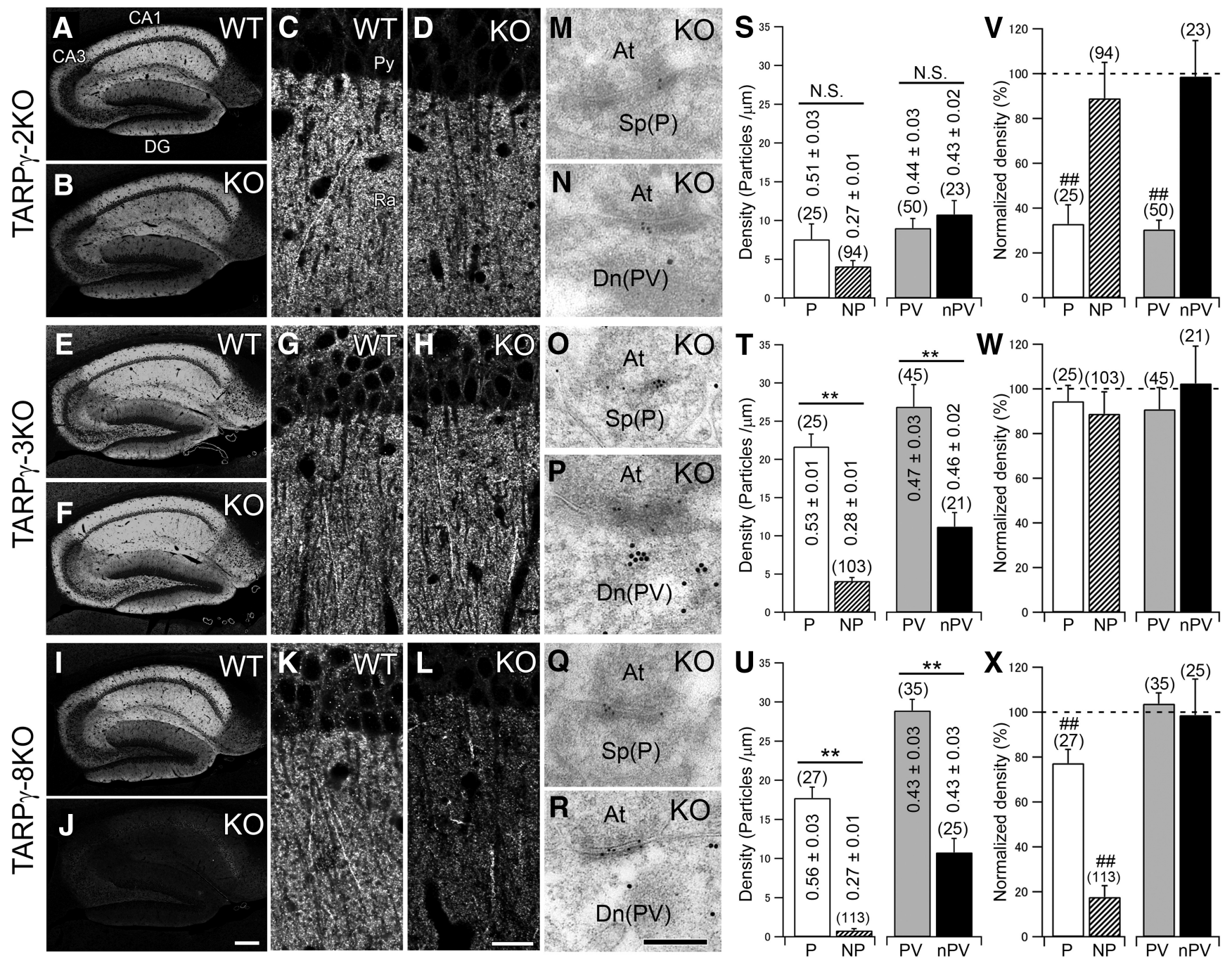

Figure 8. Differential alterations in AMPAR labeling among TARP-K0 mice. $A-L$, Immunofluorescence using pan-AMPAR antibody for AMPAR labeling in the hippocampus $(A, B, E, F, I, J)$ and $C A 1$ area $(\boldsymbol{C}, \boldsymbol{D}, \boldsymbol{G}, \boldsymbol{H}, \boldsymbol{K}, \boldsymbol{L})$ of WT $(\boldsymbol{A}, \boldsymbol{C}, \boldsymbol{E}, \boldsymbol{G}, \boldsymbol{I}, \boldsymbol{K})$ and TARP-KO $(\boldsymbol{B}, \boldsymbol{D}, \boldsymbol{F}, \boldsymbol{H}, \boldsymbol{J}, \boldsymbol{L})$ mice. Note mild reduction of AMPAR labeling in the hippocampus of TARP $\gamma$-2-K0 mice $(\boldsymbol{A}, \boldsymbol{B})$ and severe reduction in that of TARP $\gamma-8-K 0$ mice $(I, J)$. Peridendritic labeling is almost lost in TARP $\gamma$-2-KO mice $(C, D)$, whereas punctate neuropil labeling is severely lost in TARP $\gamma-8-K 0$ mice $(K, L)$. $M-R, D$ Double-labeling postembedding immunogold for AMPAR ( $\phi=10 \mathrm{~nm}$, pan-AMPAR antibody) and PV (15 nm). (S-U) The mean labeling density of AMPAR per unit total PSD length ( $\mu \mathrm{m})$ at four types of SCC synapses in TARP $\gamma-2-K O(S)$, TARP $\gamma$-3-KO (T), and TARP $\gamma-8-K O(\boldsymbol{U})$ mice. $\boldsymbol{V}-\boldsymbol{X}$, Normalized expression level of AMPARs at four SCC synapses is calculated as the percentage relative to the density of AMPAR labeling at the corresponding synapse types in control WT mice. ${ }^{* *} p<0.01$, differences in the labeling density between perforated and nonperforated synapses or between PV and non-PV synapses; N.S., not significant; $U$ test. \#\#p <0.01, comparison with the corresponding synapse type in control mice; $U$ test. A total of 192, 194, and 200 synapses were reconstructed using 72,61 , and 73 sections from TARP $\gamma$-2-K0, TARP $\gamma$-3-K0, and TARP $\gamma$-8-K0 mice, respectively. The numbers of synapses examined and the total PSD length (mean \pm SEM) are indicated in parentheses and in/on the bar, respectively. Error bars indicate SEM. Scale bars: $\boldsymbol{A}-\boldsymbol{J}$ (in $\boldsymbol{J}), 200 \mu \mathrm{m} ; \boldsymbol{C}-\boldsymbol{L}$ (in $\boldsymbol{L}$ ), $20 \mu \mathrm{m} ; \boldsymbol{M}-\boldsymbol{R}, 200 \mathrm{~nm}$.

(Fig. $9 A, B$, right; $p<0.05$ and $p<0.01$, respectively, $U$ test) and the extents of reductions were similar among GluA subunits ( $p=$ 0.42 and $p=0.45$, respectively, $\mathrm{KW}$ test). These results confirm the roles of these TARPs in skewed AMPAR expression at SCC synapses and further suggest that these TARPs have no preference for synaptic expression of any particular GluA subunits. This contrasts with the preferential functional modulation of GluA2containing AMPARs by type II TARPs (Kato et al., 2008).

\section{Compensatory changes of TARP expression}

Multiple isoforms of TARPs work for AMPAR expression and function in a synergistic manner (Menuz et al., 2008; Yamazaki et al., 2010). Finally, we examined compensatory changes in the density of TARP labeling in TARP $\gamma$-2-KO and TARP $\gamma-8$-KO mice (Fig. $10 A-F$ ). The normalized expression level was calculated as the percentage relative to the density of TARP labeling at the corresponding synapse types in control mice (Fig. 10G,H).
In TARP $\gamma$-2-KO mice, moderate but significant increases were observed for TARP $\gamma$-8 labeling at perforated, PV, and non-PV synapses (Fig. 10G; $p<0.01, p<0.05$, and $p<0.05$, respectively, $U$ test). Similar increases were observed for TARP $\gamma$-2 labeling at perforated, PV, and non-PV synapses in TARP $\gamma$-8-KO mice (Fig. $10 H ; p<0.05, p<0.01$, and $p<0.05$, respectively, $U$ test). Because all of these SCC synapses in control mice express TARP $\gamma$-2 and TARP $\gamma$-8 (Fig. 5C, D, G, H,J,L), the increases can be interpreted as compensatory upregulation. At nonperforated synapses, however, no significant increases were found for TARP $\gamma-8$ in TARP $\gamma$-2-KO mice or TARP $\gamma$-2 in TARP $\gamma-8$-KO mice (Fig. $10 G, H ; p=0.18$ and $p=0.24$, respectively, $U$ test).

\section{Discussion}

The synaptic content of AMPARs exhibits considerable disparity between different types of synapses (Nusser et al., 1998; Matsuzaki et al., 2004; Yamasaki et al., 2011). Using postembedding 


\section{A Perforated synapse}

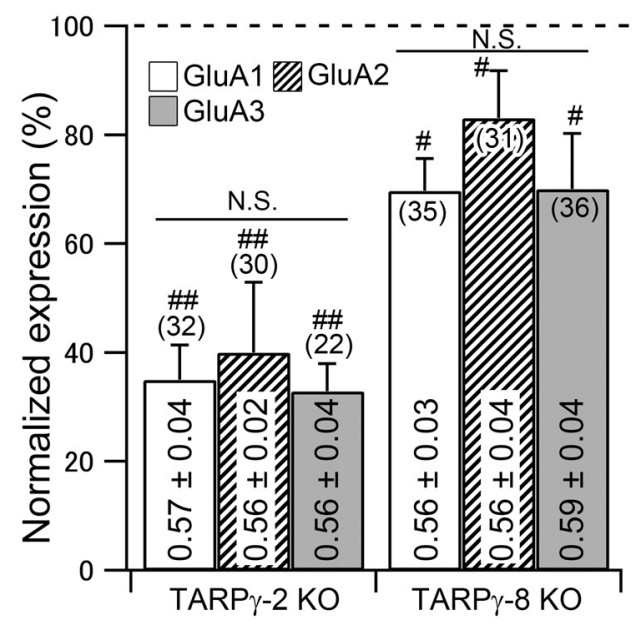

B Non-perforated synapse

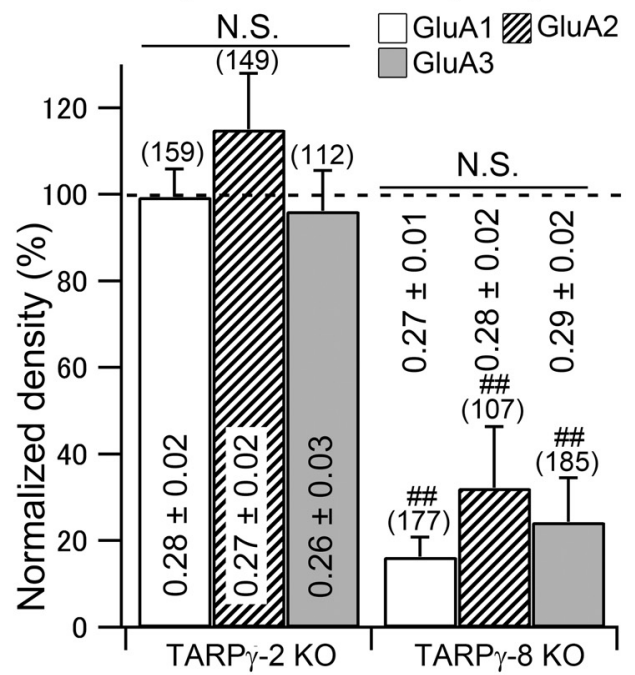

C PV synapse

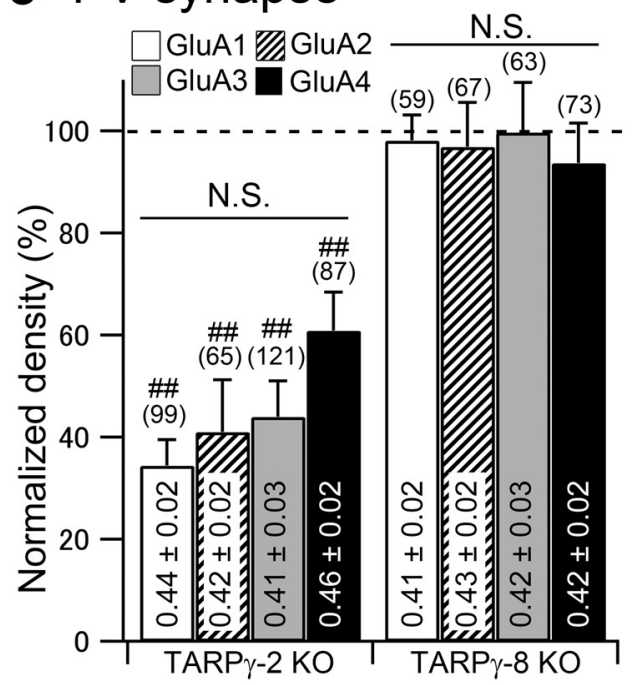

Figure 9. TARP $\gamma-2$ and TARP $\gamma-8$ promote AMPAR expression without any preference for particular GluA subunits. The normalized expression level of GluA subunits at perforated $(\boldsymbol{A})$, nonperforated ( $\boldsymbol{B}$ ), and PV ( $\boldsymbol{C}$ ) synapses in TARP $\gamma-2$-KO (left) and TARP $\gamma-8$-KO (right) mice is calculated as the percentage relative to the density of GluA labeling at the corresponding synapse types in control mice. In TARP $\gamma-2-K 0$ mice ( $\boldsymbol{A}-\boldsymbol{C}$, left), the normalized expression level is
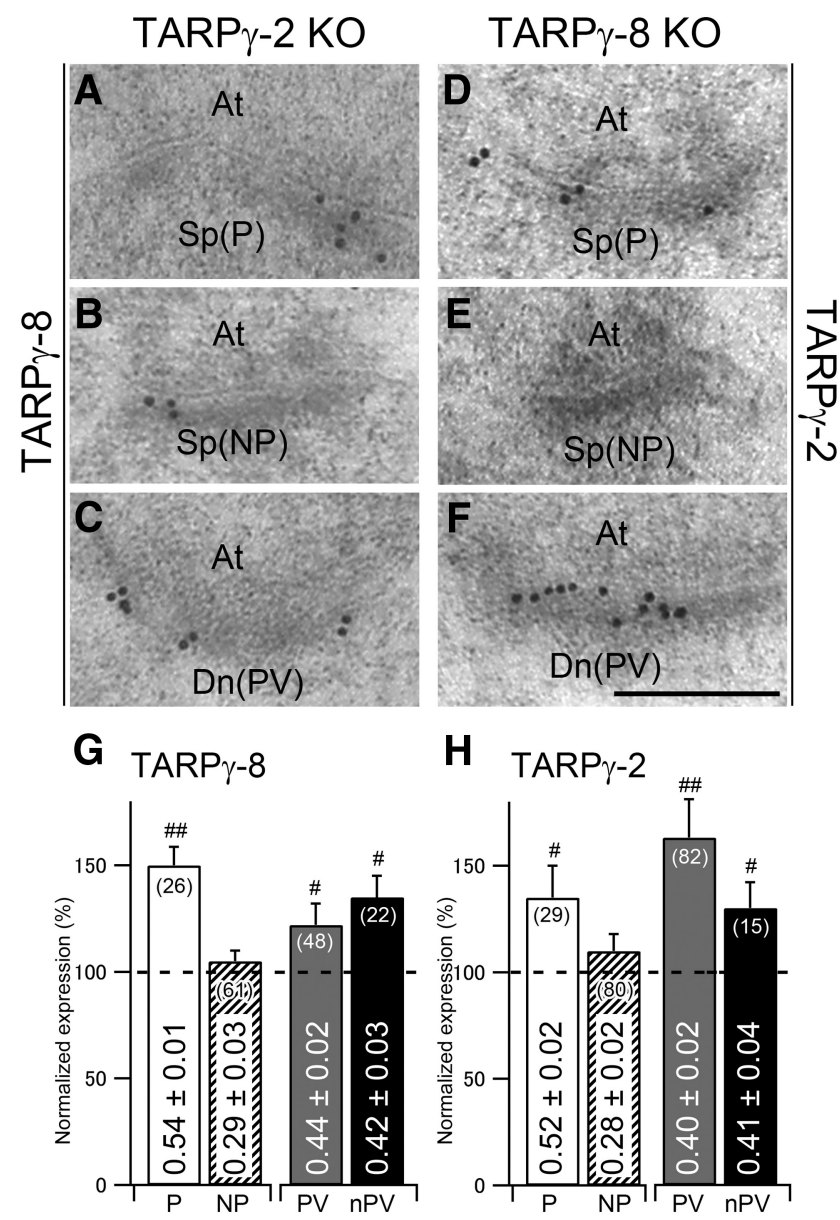

Figure 10. Compensatory increases of TARP $\gamma$ - 2 in TARP $\gamma$-8-K0 mice and TARP $\gamma$-8 in TARP $\gamma$-2-KO mice. $\boldsymbol{A}-\boldsymbol{F}$, Double-labeling postembedding immunogold EM for PV $(\boldsymbol{\phi}=15 \mathrm{~nm})$ and TARP $\gamma$-8 in TARP $\gamma$ - 2 K0 mice ( $10 \mathrm{~nm} ; \boldsymbol{A}-\boldsymbol{C}$ ) or TARP $\gamma$-2 in TARP $\gamma$ - 8 -K0 mice $(10 \mathrm{~nm} ; \boldsymbol{D}-\boldsymbol{F}$ ). $\boldsymbol{G}, \boldsymbol{H}$, Normalized expression level of TARP $\gamma$-8 labeling in TARP $\gamma$-2-KO mice (G) and TARP $\gamma$-2 labeling in TARP $\gamma$-8-K0 mice $(\boldsymbol{H})$ is calculated as the percentage relative to the density of TARP labeling at the corresponding synapse types in control mice. \#\#p $<0.01$, \#p $<0.05$ comparison with the corresponding synapse types in control mice, $U$ test. A total of 157 and 132 synapses were reconstructed using 62 and 60 sections from TARP $\gamma$-2-K0 and TARP $\gamma$-8-K0 mice, respectively. The numbers of synapses examined and the total PSD length (mean \pm SEM) are indicated in parentheses and in the bar, respectively. Scale bar, $\boldsymbol{A}-\boldsymbol{F}$ (in $\boldsymbol{F}), 200 \mathrm{~nm}$.

immunogold EM on serial ultrathin sections, we have clarified synapse-type-dependent allocations of AMPARs and TARPs in WT mice and synapse-type-specific impairments of AMPAR expression in TARP-KO mice.

Synapse-type-dependent regulation of AMPARs

Combinations of the major GluA subunits GluA1, GluA2, and GluA3 in pyramidal cells and GluA1, GluA3, and GluA4 in in-

reduced to similar extents for GluA1, GluA2, and GluA3 at perforated synapses $(\boldsymbol{A})$ and for all four subunits at PV synapses ( $($ ). Likewise, GluA1, GluA2, and GluA3 are reduced to similar extents at perforated $(\boldsymbol{A})$ and nonperforated $(\boldsymbol{B})$ synapses in TARP $\gamma$-8-K0 mice. \#\#p $<0.01$, \#p $<0.05$ comparison with the corresponding synapse types in control mice, $U$ test. Differences among three or four subunits were compared by KW test; N.S., not significant. In analyses of TARP $\gamma$-2-K0 mice, a total of 312, 244, 275, and 87 synapses were reconstructed for GluA1-GluA4 analysis from $93,62,80$, and 60 sections, respectively. In analyses of TARP $\gamma-8-K 0$ mice, a total of $271,210,289$, and 73 synapses were reconstructed for GluA1-GluA4 analysis from 78, 63, 79, and 60 sections, respectively. The numbers of synapses examined and the total PSD length (mean \pm SEM) are indicated in parentheses and in/on the bar, respectively. Statistical data are described in the text. Error bars indicate SEM. 
terneurons are consistent with previous studies using single-cell PCR and in situ hybridization (Jonas et al., 1994; Geiger et al., 1995; Garaschuk et al., 1996; Catania et al., 1998; Tsuzuki et al., 2000; Tsuzuki et al., 2001). The former expression pattern is also consistent with the prevailing notion that GluA1/GluA2 and GluA2/GluA3 heteromers are the major AMPARs and their activity-dependent insertion and replacement determine the number of synaptic AMPARs in hippocampal pyramidal cells (Wenthold et al., 1996; Shi et al., 2001). Higher densities of AMPAR labeling at perforated synapses and PV synapses than at nonperforated synapses and non-PV synapses, respectively, are consistent with previous studies (Gulyás et al., 1999; Ganeshina et al., 2004; Nicholson et al., 2006; Nicholson and Geinisman, 2009). Furthermore, our observation that the density of synaptic AMPARs is constant within given synapse types, namely, that the net number is proportional to the PSD size, matches previous studies on SCC synapses in the CA1 and mossy fiber synapses in the CA3 (Nusser et al., 1998; Takumi et al., 1999; Ganeshina et al., 2004; Shinohara et al., 2008). Therefore, the basic framework of AMPAR expression is faithfully reproduced in the present study. SCC synapses in the CA1 can be clearly categorized into highdensity (perforated and PV synapses) and low-density (nonperforated and non-PV synapses) synapses in terms of AMPAR expression. Because perforated synapses have twofold larger PSD size and fivefold higher AMPAR density than nonperforated synapses (Fig. 1E), the net number of AMPARs in the former should be approximately one order of magnitude higher than in the latter.

\section{TARP $\boldsymbol{\gamma}$-2 for high-density AMPAR expression}

To explore the underlying mechanisms, we examined PSD-95, a key scaffolding protein in the PSD that interacts TARPs directly and AMPARs indirectly via TARPs (Chen et al., 2000; Tomita et al., 2004). Unexpectedly, the density of PSD-95 labeling was fairly constant across the four types of SCC synapses, indicating that the total number of PSD-95 is determined in linear relationship with the PSD size or area regardless of the type of SCC synapse.

In contrast, the density of TARPs was highly variable depending on synapse type and TARP isoform. Of three classical TARPs expressed in hippocampal neurons, we found that the density of AMPAR labeling was closely related to that of TARP $\gamma$ - 2 labeling. This was observed from the moderate immunogold labeling for TARP $\gamma$-2 at perforated synapses versus the background level at nonperforated synapses and high transcription levels of TARP $\gamma-2$ in PV-positive interneurons versus low levels in pyramidal cells and other interneurons. Importantly, in TARP $\gamma-2-\mathrm{KO}$ mice, there was a substantial decrease in the density of AMPAR labeling at perforated and PV synapses, resulting in a virtual loss of AMPAR density disparity at SCC synapses. These results show that synaptic inclusion of TARP $\gamma$-2 potently increases AMPAR expression and transforms low-density synapses into highdensity ones. This potency is also true at cerebellar mossy fibergranule cell synapses, where AMPAR function and expression are completely lost in the spontaneous TARP $\gamma$-2-defective mutant stargazer and TARP $\gamma$-2-KO mice (Letts et al., 1998; Hashimoto et al., 1999; Chen et al., 2000; Yamasaki et al., 2010). As for the normal AMPAR expression level at non-PV synapses in TARP $\gamma$-2-KO mice, low-density expression of AMPARs at the synapses might be functionally compensated by other functionally redundant TARPs (Tomita et al., 2003; Letts et al., 2005; Rouach et al., 2005; Milstein et al., 2007; Menuz et al., 2008).

\section{TARP $\boldsymbol{\gamma} \mathbf{- 8}$ for low and basal AMPAR expression}

Changes in the density of synaptic AMPARs were subtle, if any existed, at most SCC synapses in TARP $\gamma$-3-KO and TARP $\gamma-8$-KO mice. Severe reduction of AMPAR density was only noted at nonperforated synapses in TARP $\gamma-8$-KO mice. At nonperforated synapses, TARP $\gamma-8$ is the only classical TARP expressed in WT mice, whereas no compensatory upregulation of TARP $\gamma$-2 occurred in TARP $\gamma$-8-KO mice. These findings show that TARP $\gamma-8$ plays an essential role in maintaining the lowdensity expression of AMPARs at nonperforated synapses. Despite compensatory upregulation of TARP $\gamma-8$, the density of AMPAR labeling was severely reduced at perforated and PV synapses in TARP $\gamma$-2-KO mice. In contrast, AMPAR density was normally maintained at perforated and PV synapses in TARP $\gamma$-8-KO mice, where compensatory upregulation of TARP $\gamma$-2 occurred. These contrasting phenotypes, together with no apparent changes in TARP $\gamma$-3-KO mice, suggest that TARPs have differential potencies to promote synaptic AMPAR expression in the order of TARP $\gamma$-2 $>$ TARP $\gamma-8>$ TARP $\gamma$-3.

Nevertheless, at the histological level, diminished AMPAR immunolabeling in the hippocampus was outstanding in TARP $\gamma$-8-KO mice compared with TARP $\gamma$-2-KO mice. This should reflect, at least partly, the loss of AMPARs from the most numerous types of SCC synapses (i.e., nonperforated synapses) in TARP $\gamma$-8-KO mice. The large deficit may also be ascribed to the loss of extrasynaptic AMPARs in TARP $\gamma$-8-KO mice for the following reasons: TARP $\gamma-8$ is expressed on both the synaptic and extrasynaptic membranes, in contrast to the concentrated synaptic expression of TARP $\gamma$-2 (Fukaya et al., 2006; Inamura et al., 2006). In parallel with the distinct compartmentalized expression, TARP $\gamma$ - 8 controls extrasynaptic pools of AMPARs and synaptic expression (Rouach et al., 2005; Fukaya et al., 2006), whereas TARP $\gamma$-2 is not required for retaining extrasynaptic AMPARs (Jackson and Nicoll, 2011a). Despite much lower receptor density on the extrasynaptic site than at the synaptic site, the total number of extrasynaptic AMPARs should outnumber the total synaptic AMPARs, taking into account the vast area of the neuronal surface. Therefore, the loss of extrasynaptic AMPARs in TARP $\gamma$-8-KO mice should have a great impact on the hippocampal content of AMPARs. Therefore, it can be assumed that TARP $\gamma-8$ is critically involved in low-density or basal expression of AMPARs at nonperforated synapses and on the extrasynaptic surface.

\section{Possible mechanisms of TARP-dependent regulation of synaptic AMPARs}

How are these TARPs involved in the distinct density control of synaptic AMPARs? At most, four TARPs assemble with tetrameric AMPAR channels, and this TARP/AMPAR stoichiometry varies depending on the neuronal cell type and TARP expression levels (Shi et al., 2009; Kim et al., 2010; Hastie et al., 2013). AMPARs in CA1 pyramidal cells are normally saturated with four molecules of TARP $\gamma$-8. However, in TARP $\gamma$-8-KO pyramidal cells, just one TARP molecule associates with individual AMPARs (Shi et al., 2009), suggesting that the remaining TARP $\gamma-2$ and/or TARP $\gamma-3$ have a smaller stoichiometry than TARP $\gamma$-8. In support of this notion, one molecule of TARP $\gamma-2$ is sufficient to modulate AMPAR activity in cerebellar granule cells (Kim et al., 2010). Moreover, Erbin, a member of the leucine-rich repeat and PDZ domain family, is specifically localized at excitatory synapses on PV-positive interneurons, interacts with and increases the stability of TARP $\gamma$-2, and thereby increases synaptic AMPAR expression (Tao et al., 2013). Therefore, the small TARP/AMPAR stoichiometry of TARP $\gamma$-2 and the presence of its specific molecular partner might endow this isoform with a 
high capacity to accommodate AMPAR at perforated and PV synapses, thereby enabling high AMPAR conductance for reliable neuronal output (Nicholson et al., 2006; Pelkey et al., 2008). In comparison, nonperforated synapses are thought to be highly plastic but usually "silent." It has been proposed that insertion of AMPARs into small, nonperforated synapses increases the size of PSD and spines and eventually leads to the formation of perforated synapses (Lüscher et al., 2000; Matsuzaki et al., 2004). Therefore, we assume that the selective expression of TARP $\gamma-8$, with large TARP/ AMPAR stoichiometry, is suited to accommodate small numbers of AMPARs at nonperforated synapses, which might be transformed into AMPAR-rich perforated synapses by incorporating TARP $\gamma$-2 upon enhanced neural activities.

TARPs are important targets of calmodulin-dependent protein kinase-II (CaMKII) and protein kinase C (PKC) in synaptic plasticity (Jackson and Nicoll, 2011b). Activity-dependent phosphorylation of TARP $\gamma-2$ by CaMKII controls the interaction with PSD-95 (Opazo et al., 2010; Sumioka et al., 2010), thereby enhancing the synaptic delivery and stabilization of AMPARs (Tomita et al., 2005; Kessels et al., 2009). Given that phosphorylation of TARP $\gamma-2$ and TARP $\gamma-8$ is differentially regulated by CaMKII and PKC (Inamura et al., 2006), it would be of considerable interest to pursue how TARP-isoform-specific phosphorylation contributes to activity-dependent regulation of synaptic AMPAR expression in basal transmission and during synaptic plasticity at a given type of SCC synapse.

In conclusion, TARP $\gamma$-2 and TARP $\gamma$ - 8 specifically and cooperatively regulate the disparity of AMPAR expression at hippocampal SCC synapses through different cellular expression and synaptic targeting and also through their different potencies in accommodating AMPARs on the platform of PSD.

\section{References}

Barbour B, Brunel N, Hakim V, Nadal JP (2007) What can we learn from synaptic weight distributions? Trends Neurosci 30:622-629. CrossRef Medline

Barry MF, Ziff EB (2002) Receptor trafficking and the plasticity of excitatory synapses. Curr Opin Neurobiol 12:279-286. CrossRef Medline

Bats C, Groc L, Choquet D (2007) The interaction between Stargazin and PSD-95 regulates AMPA receptor surface trafficking. Neuron 53:719734. CrossRef Medline

Baude A, Nusser Z, Molnár E, McIlhinney RA, Somogyi P (1995) Highresolution immunogold localization of AMPA type glutamate receptor subunits at synaptic and non-synaptic sites in rat hippocampus. Neuroscience 69:1031-1055. CrossRef Medline

Béique JC, Andrade R (2003) PSD-95 regulates synaptic transmission and plasticity in rat cerebral cortex. J Physiol 546:859-867. CrossRef Medline

Brunel N, Hakim V, Isope P, Nadal JP, Barbour B (2004) Optimal information storage and the distribution of synaptic weights: perceptron versus Purkinje cell. Neuron 43:745-757. Medline

Catania MV, Bellomo M, Giuffrida R, Giuffrida R, Stella AM, Albanese V (1998) AMPA receptor subunits are differentially expressed in parvalbumin- and calretinin-positive neurons of the rat hippocampus. Eur J Neurosci 10:3479-3490. CrossRef Medline

Chen L, Chetkovich DM, Petralia RS, Sweeney NT, Kawasaki Y, Wenthold RJ, Bredt DS, Nicoll RA (2000) Stargazin regulates synaptic targeting of AMPA receptors by two distinct mechanisms. Nature 408:936-943. CrossRef Medline

Desmond NL, Weinberg RJ (1998) Enhanced expression of AMPA receptor protein at perforated axospinous synapses. Neuroreport 9:857-860. CrossRef Medline

El-Husseini AE, Schnell E, Chetkovich DM, Nicoll RA, Bredt DS (2000) PSD-95 involvement in maturation of excitatory synapses. Science 290: 1364-1368. Medline

Fuentealba P, Begum R, Capogna M, Jinno S, Márton LF, Csicsvari J, Thomson A, Somogyi P, Klausberger T (2008) Ivy cells: a population of nitric-oxideproducing, slow-spiking GABAergic neurons and their involvement in hippocampal network activity. Neuron 57:917-929. CrossRef Medline
Fukaya M, Watanabe M (2000) Improved immunohistochemical detection of postsynaptically located PSD-95/SAP90 protein family by protease section pretreatment: a study in the adult mouse brain. J Comp Neurol 426:572-586. Medline

Fukaya M, Yamazaki M, Sakimura K, Watanabe M (2005) Spatial diversity in gene expression for VDCCgamma subunit family in developing and adult mouse brains. Neurosci Res 53:376-383. CrossRef Medline

Fukaya M, Tsujita M, Yamazaki M, Kushiya E, Abe M, Akashi K, Natsume R, Kano M, Kamiya H, Watanabe M, Sakimura K (2006) Abundant distribution of TARP gamma-8 in synaptic and extrasynaptic surface of hippocampal neurons and its major role in AMPA receptor expression on spines and dendrites. Eur J Neurosci 24:2177-2190. CrossRef Medline

Ganeshina O, Berry RW, Petralia RS, Nicholson DA, Geinisman Y (2004) Differences in the expression of AMPA and NMDA receptors between axospinous perforated and nonperforated synapses are related to the configuration and size of postsynaptic densities. J Comp Neurol 468:86-95. CrossRef Medline

Garaschuk O, Schneggenburger R, Schirra C, Tempia F, Konnerth A (1996) Fractional $\mathrm{Ca} 2+$ currents through somatic and dendritic glutamate receptor channels of rat hippocampal CA1 pyramidal neurones. J Physiol 491:757-772. CrossRef Medline

Geiger JR, Melcher T, Koh DS, Sakmann B, Seeburg PH, Jonas P, Monyer H (1995) Relative abundance of subunit mRNAs determines gating and $\mathrm{Ca} 2+$ permeability of AMPA receptors in principal neurons and interneurons in rat CNS. Neuron 15:193-204. CrossRef Medline

Glass GV, Peckham PD, Sanders JR (1972) Consequences of failure to meet the assumptions underlying the fixed effects analysis of variance and covariance. Rev Educ Res 42:237-288. CrossRef

Gulyás AI, Megías M, Emri Z, Freund TF (1999) Total number and ratio of excitatory and inhibitory synapses converging onto single interneurons of different types in the CA1 area of the rat hippocampus. J Neurosci 19: 10082-10097. Medline

Hashimoto K, Fukaya M, Qiao X, Sakimura K, Watanabe M, Kano M (1999) Impairment of AMPA receptor function in cerebellar granule cells of ataxic mutant mouse stargazer. J Neurosci 19:6027-6036. Medline

Hastie P, Ulbrich MH, Wang HL, Arant RJ, Lau AG, Zhang Z, Isacoff EY, Chen L (2013) AMPA receptor/TARP stoichiometry visualized by single-molecule subunit counting. Proc Natl Acad Sci U S A 110:51635168. CrossRef Medline

Hollmann M, Heinemann S (1994) Cloned glutamate receptors. Annu Rev Neurosci 17:31-108. CrossRef Medline

Huganir RL, Nicoll RA (2013) AMPARs and synaptic plasticity: the last 25 years. Neuron 80:704-717. CrossRef Medline

Inamura $\mathrm{M}$, Itakura $\mathrm{M}$, Okamoto $\mathrm{H}$, Hoka S, Mizoguchi A, Fukazawa $\mathrm{Y}$, Shigemoto R, Yamamori S, Takahashi M (2006) Differential localization and regulation of stargazin-like protein, gamma-8 and stargazin in the plasma membrane of hippocampal and cortical neurons. Neurosci Res 55:45-53. CrossRef Medline

Jackson AC, Nicoll RA (2011a) Stargazin (TARP gamma-2) is required for compartment-specific AMPA receptor trafficking and synaptic plasticity in cerebellar stellate cells. J Neurosci 31:3939-3952. CrossRef Medline

Jackson AC, Nicoll RA (2011b) The expanding social network of ionotropic glutamate receptors: TARPs and other transmembrane auxiliary subunits. Neuron 70:178-199. CrossRef Medline

Jonas P, Racca C, Sakmann B, Seeburg PH, Monyer H (1994) Differences in $\mathrm{Ca} 2+$ permeability of AMPA-type glutamate receptor channels in neocortical neurons caused by differential GluR-B subunit expression. Neuron 12:1281-1289. CrossRef Medline

Kato AS, Siuda ER, Nisenbaum ES, Bredt DS (2008) AMPA receptor subunit-specific regulation by a distinct family of type II TARPs. Neuron 59:986-996. CrossRef Medline

Kessels HW, Kopec CD, Klein ME, Malinow R (2009) Roles of stargazin and phosphorylation in the control of AMPA receptor subcellular distribution. Nat Neurosci 12:888-896. CrossRef Medline

Kim KS, Yan D, Tomita S (2010) Assembly and stoichiometry of the AMPA receptor and transmembrane AMPA receptor regulatory protein complex. J Neurosci 30:1064-1072. CrossRef Medline

Kubota Y, Hatada SN, Kawaguchi Y (2009) Important factors for the threedimensional reconstruction of neuronal structures from serial ultrathin sections. Front Neural Circuits 3:4. Medline

Letts VA, Felix R, Biddlecome GH, Arikkath J, Mahaffey CL, Valenzuela A, Bartlett FS 2nd, Mori Y, Campbell KP, Frankel WN (1998) The mouse 
stargazer gene encodes a neuronal $\mathrm{Ca} 2+$-channel gamma subunit. Nat Genet 19:340-347. CrossRef Medline

Letts VA, Mahaffey CL, Beyer B, Frankel WN (2005) A targeted mutation in Cacng4 exacerbates spike-wave seizures in stargazer (Cacng2) mice. Proc Natl Acad Sci U S A 102:2123-2128. CrossRef Medline

Lüscher C, Nicoll RA, Malenka RC, Muller D (2000) Synaptic plasticity and dynamic modulation of the postsynaptic membrane. Nat Neurosci 3:545550. CrossRef Medline

Maheshwari A, Nahm WK, Noebels JL (2013) Paradoxical proepileptic response to NMDA receptor blockade linked to cortical interneuron defect in stargazer mice. Front Cell Neurosci 7:156. Medline

Malinow R, Malenka RC (2002) AMPA receptor trafficking and synaptic plasticity. Annu Rev Neurosci 25:103-126. CrossRef Medline

Matsuzaki M, Honkura N, Ellis-Davies GC, Kasai H (2004) Structural basis of long-term potentiation in single dendritic spines. Nature 429:761-766. CrossRef Medline

Meek GA (1976) Practical electron microscopy for biologists. New York: Wiley.

Menuz K, O’Brien JL, Karmizadegan S, Bredt DS, Nicoll RA (2008) TARP redundancy is critical for maintaining AMPA receptor function. J Neurosci 28:8740-8746. CrossRef Medline

Milstein AD, Zhou W, Karimzadegan S, Bredt DS, Nicoll RA (2007) TARP subtypes differentially and dose-dependently control synaptic AMPA receptor gating. Neuron 55:905-918. CrossRef Medline

Mishina M, Sakimura K (2007) Conditional gene targeting on the pure C57BL/6 genetic background. Neurosci Res 58:105-112. CrossRef Medline

Miura E, Fukaya M, Sato T, Sugihara K, Asano M, Yoshioka K, Watanabe M (2006) Expression and distribution of JNK/SAPK-associated scaffold protein JSAP1 in developing and adult mouse brain. J Neurochem 97: 1431-1446. CrossRef Medline

Nakamura M, Sato K, Fukaya M, Araishi K, Aiba A, Kano M, Watanabe M (2004) Signaling complex formation of phospholipase Cbeta4 with metabotropic glutamate receptor type lalpha and 1,4,5-trisphosphate receptor at the perisynapse and endoplasmic reticulum in the mouse brain. Eur J Neurosci 20:2929-2944. CrossRef Medline

Nicholson DA, Geinisman Y (2009) Axospinous synaptic subtype-specific differences in structure, size, ionotropic receptor expression, and connectivity in apical dendritic regions of rat hippocampal CA1 pyramidal neurons. J Comp Neurol 512:399-418. CrossRef Medline

Nicholson DA, Trana R, Katz Y, Kath WL, Spruston N, Geinisman Y (2006) Distance-dependent differences in synapse number and AMPA receptor expression in hippocampal CA1 pyramidal neurons. Neuron 50:431-442. CrossRef Medline

Nusser Z, Lujan R, Laube G, Roberts JD, Molnár E, Somogyi P (1998) Cell type and pathway dependence of synaptic AMPA receptor number and variability in the hippocampus. Neuron 21:545-559. CrossRef Medline

Opazo P, Labrecque S, Tigaret CM, Frouin A, Wiseman PW, De Koninck P, Choquet D (2010) CaMKII triggers the diffusional trapping of surface AMPARs through phosphorylation of stargazin. Neuron 67:239-252. CrossRef Medline

Opazo P, Sainlos M, Choquet D (2012) Regulation of AMPA receptor surface diffusion by PSD-95 slots. Curr Opin Neurobiol 22:453-460. CrossRef Medline

Pelkey KA, Topolnik L, Yuan XQ, Lacaille JC, McBain CJ (2008) Statedependent cAMP sensitivity of presynaptic function underlies metaplasticity in a hippocampal feedforward inhibitory circuit. Neuron 60: 980-987. CrossRef Medline

Racca C, Stephenson FA, Streit P, Roberts JD, Somogyi P (2000) NMDA receptor content of synapses in stratum radiatum of the hippocampal CA1 area. J Neurosci 20:2512-2522. Medline

Rouach N, Byrd K, Petralia RS, Elias GM, Adesnik H, Tomita S, Karimzadegan S, Kealey C, Bredt DS, Nicoll RA (2005) TARP gamma-8 controls hippocampal AMPA receptor number, distribution and synaptic plasticity. Nat Neurosci 8:1525-1533. CrossRef Medline

Schnell E, Sizemore M, Karimzadegan S, Chen L, BredtDS, Nicoll RA (2002) Direct interactions between PSD-95 and stargazin control synaptic AMPA receptor number. Proc Natl Acad Sci U S A 99:13902-13907. CrossRef Medline

Shi S, Hayashi Y, Esteban JA, Malinow R (2001) Subunit-specific rules governing AMPA receptor trafficking to synapses in hippocampal pyramidal neurons. Cell 105:331-343. CrossRef Medline

Shi Y, Lu W, Milstein AD, Nicoll RA (2009) The stoichiometry of AMPA receptors and TARPs varies by neuronal cell type. Neuron 62:633-640. CrossRef Medline

Shinohara Y, Hirase H, Watanabe M, Itakura M, Takahashi M, Shigemoto R (2008) Left-right asymmetry of the hippocampal synapses with differential subunit allocation of glutamate receptors. Proc Natl Acad Sci U S A 105:19498-19503. CrossRef Medline

Slot JW, Geuze HJ (1985) A new method of preparing gold probes for multiple-labeling cytochemistry. Eur J Cell Biol 38:87-93. Medline

Small JV (1968) Measurement of Section Thickness. Abstracts of the Fourth European Regional Conference on Electron Microscopy Vol 1:609-610.

Somogyi P, Klausberger T (2005) Defined types of cortical interneurone structure space and spike timing in the hippocampus. J Physiol 562:9-26. CrossRef Medline

Song I, Huganir RL (2002) Regulation of AMPA receptors during synaptic plasticity. Trends Neurosci 25:578-588. CrossRef Medline

Sorra KE, Harris KM (2000) Overview on the structure, composition, function, development, and plasticity of hippocampal dendritic spines. Hippocampus 10:501-511. Medline

Soto D, Coombs ID, Renzi M, Zonouzi M, Farrant M, Cull-Candy SG (2009) Selective regulation of long-form calcium-permeable AMPA receptors by an atypical TARP, gamma-5. Nat Neurosci 12:277-285. CrossRef Medline

Sumioka A, Yan D, Tomita S (2010) TARP phosphorylation regulates synaptic AMPA receptors through lipid bilayers. Neuron 66:755-767. CrossRef Medline

Takumi Y, Ramírez-León V, Laake P, Rinvik E, Ottersen OP (1999) Different modes of expression of AMPA and NMDA receptors in hippocampal synapses. Nat Neurosci 2:618-624. CrossRef Medline

Tao Y, Chen YJ, Shen C, Luo Z, Bates CR, Lee D, Marchetto S, Gao TM, Borg JP, Xiong WC, Mei L (2013) Erbin interacts with TARP gamma-2 for surface expression of AMPA receptors in cortical interneurons. Nat Neurosci 16:290-299. CrossRef Medline

Tomita S, Chen L, Kawasaki Y, Petralia RS, Wenthold RJ, Nicoll RA, Bredt DS (2003) Functional studies and distribution define a family of transmembrane AMPA receptor regulatory proteins. J Cell Biol 161:805-816. CrossRef Medline

Tomita S, Fukata M, Nicoll RA, Bredt DS (2004) Dynamic interaction of stargazin-like TARPs with cycling AMPA receptors at synapses. Science 303:1508-1511. CrossRef Medline

Tomita S, Adesnik H, Sekiguchi M, Zhang W, Wada K, Howe JR, Nicoll RA, Bredt DS (2005) Stargazin modulates AMPA receptor gating and trafficking by distinct domains. Nature 435:1052-1058. CrossRef Medline

Tsuzuki K, Isa T, Ozawa S (2000) Subunit composition of AMPA receptors expressed by single hippocampal neurons. Neuroreport 11:3583-3587. CrossRef Medline

Tsuzuki K, Lambolez B, Rossier J, Ozawa S (2001) Absolute quantification of AMPA receptor subunit mRNAs in single hippocampal neurons. J Neurochem 77:1650-1659. CrossRef Medline

Watanabe M, Fukaya M, Sakimura K, Manabe T, Mishina M, Inoue Y (1998) Selective scarcity of NMDA receptor channel subunits in the stratum lucidum (mossy fibre-recipient layer) of the mouse hippocampal CA3 subfield. Eur J Neurosci 10:478-487. CrossRef Medline

Wenthold RJ, Petralia RS, Blahos J II, Niedzielski AS (1996) Evidence for multiple AMPA receptor complexes in hippocampal CA1/CA2 neurons. J Neurosci 16:1982-1989. Medline

Yamasaki M, Matsui M, Watanabe M (2010) Preferential localization of muscarinic M1 receptor on dendritic shaft and spine of cortical pyramidal cells and its anatomical evidence for volume transmission. J Neurosci 30:4408-4418. CrossRef Medline

Yamasaki M, Miyazaki T, Azechi H, Abe M, Natsume R, Hagiwara T, Aiba A, Mishina M, Sakimura K, Watanabe M (2011) Glutamate receptor delta2 is essential for input pathway-dependent regulation of synaptic AMPAR contents in cerebellar Purkinje cells. J Neurosci 31:3362-3374. CrossRef Medline

Yamazaki M, Ohno-Shosaku T, Fukaya M, Kano M, Watanabe M, Sakimura K (2004) A novel action of stargazin as an enhancer of AMPA receptor activity. Neurosci Res 50:369-374. CrossRef Medline

Yamazaki M, Fukaya M, Hashimoto K, Yamasaki M, Tsujita M, Itakura M, Abe M, Natsume R, Takahashi M, Kano M, Sakimura K, Watanabe M (2010) TARPs gamma- 2 and gamma-7 are essential for AMPA receptor expression in the cerebellum. Eur J Neurosci 31:2204-2220. CrossRef Medline

Ziff EB (2007) TARPs and the AMPA receptor trafficking paradox. Neuron 53:627-633. CrossRef Medline 